\title{
A Survey on the Effect of Graph Operations on the Domination Number of a Graph
}

\author{
Yamuna $\mathrm{M}^{\# 1}$ and Karthika $\mathrm{K}^{\# 2}$ \\ SAS, VIT University, Vellore, Tamilnadu, India, 632014. \\ ${ }^{1}$ myamuna@vit.ac.in \\ ${ }^{2}$ Karthika.k@vit.ac.in
}

\begin{abstract}
A dominating set of $G$ is a set of vertices of $G$ such that every vertex in $V$ - $D$ is adjacent to a vertex in $D$. The domination number of $G$, denoted by $\gamma(G)$, is the minimum cardinality of a dominating set. Different kinds of graph operations have different outcomes on the domination number of a graph. In this paper we present a brief survey on the impact of different kinds of graph operation on the domination number of a graph.
\end{abstract}

Keyword - Domination, Domination Number, Graph Operation.

\section{INTRODUCTION}

The study of domination number in graph theory was introduced by Claude Berge in 1958, on his book "Theory of Graphs and its Applications" [1]. But domination number was studied in the name of coefficient of external stability. At the first time the name dominating set and domination number was used by Oyestein Ore in [2]. At the beginning stage the domination number was denoted by d ( G ). Later, in 1977, the notation $\gamma(\mathrm{G})$ is used to denote the domination number in [3], by E. J. Cockayne and S. T. Hedetniemi. The literature on domination has been surveyed in detail in two famous books by T.W. Haynes, S.T. Hedetniemi, and P.J. Slater [4][5].

Since the evolution of domination theory, types of domination are also established and studied by many researchers. But the original dominating set is the base for all types of domination. Different kinds of graph operations change the graphs and hence influence the domination number of the graph also. In this survey we concentrate on the effect of various kinds of graph operations on the domination number. There are several results relating graph operations and different types of domination. But we restrict our survey only to graph operations and dominating sets. Several results are available in this regard, and many have been omitted in this brief survey. We apologize to the authors for the omission. Many results omitted here can be found in [4][5] and in the articles in the reference section. This survey is restricted to presentation of possible results that describe the effects of the graph operations on the domination number of a graph.

\section{GRAPH THEORY TERMINOLOGY AND CONCEPTS}

All graphs in this paper are undirected and simple. Let $\mathrm{G}=(\mathrm{V}, \mathrm{E})$ be a graph with the vertex set $\mathrm{V}$ of order $\mathrm{V}(\mathrm{G}) \mid=\mathrm{n}$ and edge set $\mathrm{E}$ of size $|\mathrm{E}|=\mathrm{m}$, and let $\mathrm{v}$ be a vertex in $\mathrm{V}$. The open neighborhood of $\mathrm{v}$ is $\mathrm{N}(\mathrm{v})=$ $\{\mathrm{u} \in \mathrm{V}(\mathrm{G}) \mid(\mathrm{u} v) \in \mathrm{E}(\mathrm{G})\}$ and the closed neighborhood of $\mathrm{v}$ is $\mathrm{N}[\mathrm{v}]=\{\mathrm{v}\} \cup \mathrm{N}(\mathrm{v})$. We indicate that $\mathrm{u}$ is adjacent to $\mathrm{v}$ by writing $\mathrm{u} \perp \mathrm{v}$.

The degree of $\mathrm{v}$ in $\mathrm{G}$ is denoted by $\mathrm{d}(\mathrm{v})$. The vertex $\mathrm{v}$ is said to be isolated if $\operatorname{deg}(\mathrm{v})=0$ and it is a pendant vertex if $\operatorname{deg}(\mathrm{v})=1$, while a support vertex of $\mathrm{T}$ is a vertex adjacent to a pendant vertex. A vertex which is adjacent to two or more leaves is called a strong support vertex. A cut vertex of a graph is one whose removal increases the number of components, that is if $\mathrm{v}$ is a cut vertex of a connected graph $\mathrm{G}$, then $\mathrm{G}-\{\mathrm{v}\}$ is disconnected. A maximal connected subgraph without a cutvertex is called a block. A block of a graph $\mathrm{G}$ containing only one cut vertex is called an end block of $\mathrm{G}$.

The connectivity $\mathrm{k}=\mathrm{k}$ ( $\mathrm{G}$ ) of a graph $\mathrm{G}$ is the minimum number of vertices whose removal results in a disconnected or trivial graph. A set of independent edges in a graph $\mathrm{G}$ is called a matching of G. A 1 - factor or a perfect matching of a graph is a partition of its vertices into adjacent pairs.

$P_{n}, C_{n}, K_{n}$, denotes the path, cycle and complete graph with $n$ vertices respectively. The wheel graph is denoted by $\mathrm{W}_{\mathrm{n}}$, and it is defined as $\mathrm{K}_{1}+\mathrm{C}_{\mathrm{n}-1}$. We denote the radius and diameter of $\mathrm{G}$ by $\operatorname{rad}(\mathrm{G})$ and $\operatorname{diam}$ $(\mathrm{G})$, respectively. The minimum and maximum degree on the vertices of $\mathrm{G}$ is denoted by $\delta(\mathrm{G})$ and $\Delta(\mathrm{G})$ respectively. If $\delta(\mathrm{G})=\Delta(\mathrm{G})=\mathrm{r}$, then all points have the same degree and $\mathrm{G}$ is called regular of degree $\mathrm{r}$. The regular graphs are those of degree 3 , such graphs are called cubic. The complement $\overline{\mathrm{G}}$ of a graph $\mathrm{G}$ also has V ( G ) as its vertex set, but two vertices are adjacent in $\overline{\mathrm{G}}$ if and only if they are not adjacent in G. 
A bipartite graph $G$ is a graph whose vertex set $V(G)$ can be partitioned into two subsets $V_{1}(G)$ and $V_{2}$ $(G)$ such that every edge of $G$ joins $V_{1}(G)$ with $V_{2}(G)$. If $G$ contains every vertex joining $V_{1}$ and $V_{2}$, then $G$ is a complete bipartite graph. If $V_{1}$ and $V_{2}$ have $m$ and $n$ vertices, it is denoted by $K_{m, n}$.

A planar graph is a graph that can be embedded in the plane, that is, it can be drawn on the plane in such a way that its edges intersect only at their endpoints. In other words, it can be drawn in such a way that no edges cross each other. A planar graph is outerplanar if it can be embedded in the plane so that all its vertices lie on the same face. We usually choose this face to be the exterior face. For an inner face $f$ of $G, f$ is said to be an internal triangle if it is not adjacent to the exterior face. An outerplanar graph $\mathrm{G}$ is maximal outerplanar if no line can be added without losing outerplanarity.

A hamiltonian path of $\mathrm{G}$ is a path passing exactly once through every vertex of $\mathrm{G}$. A hamiltonian cycle is a closed hamiltonian path. The circumference c ( $G$ ) is the length of a longest cycle of $G$. A graph $G$ is hamiltonian if its circumference is equal to $\mathrm{n}$. For details of on graph theory we refer to [6].

A dominating set, denoted by DS, of G is a set of vertices of G such that every vertex in V - D is adjacent to a vertex in D. The domination number of G, denoted by $\gamma(\mathrm{G})$, is the minimum cardinality of a DS. The cardinality of any minimum dominating set ( MDS ) for $\mathrm{G}$ is called the domination number of $\mathrm{G}$ and it is denoted by $\gamma(\mathrm{G}) \cdot \gamma$ - set denotes a dominating set for $\mathrm{G}$ with minimum cardinality.

A vertex $\mathrm{v}$ is said to be selfish in the $\gamma-$ set $\mathrm{D}$, if $\mathrm{v}$ is needed only to dominate itself. A vertex $\mathrm{v}$ is said to be good if there is a $\gamma$ - set of $\mathrm{G}$ containing $\mathrm{v}$. If there is no $\gamma$ - set of $\mathrm{G}$ containing $\mathrm{v}$, then $\mathrm{v}$ is said to be a bad vertex. A graph $G$ is said to be excellent if every vertex of $G$ is good. A vertex $v$ is said to be a, down vertex if $\gamma$ $(G-v)<\gamma(G)$, level vertex if $\gamma(G-v)=\gamma(G)$, up vertex if $\gamma(G-v)>\gamma(G)$. The private neighborhood of $v \in D$, denoted by $p n[v, D]$, is defined by $p n[v, D]=N[v]-N[D-\{v\}]$.

A domatic partition of a graph $G=(V, E)$ is a partition of $V$ into disjoint sets $V_{1}, V_{2}, \ldots, V_{K}$ such that each $V_{i}$ is a dominating set for $\mathrm{G}$. The domatic number is the maximum number of such disjoint sets and it is denoted by $\mathrm{d}(\mathrm{G})$. A dominating set $\mathrm{D}$ is said to be an independent dominating set if no two vertices in D are adjacent. A set of vertices $\mathrm{D}$ in a graph $\mathrm{G}$ is called a clique dominating set if every two vertices in $\mathrm{D}$ are adjacent. A vertex in $\mathrm{V}-\mathrm{D}$ is $\mathrm{k}$ - dominated if it is dominated by at least 2 - vertices in $\mathrm{D}$, that is $|\mathrm{N}(\mathrm{v}) \cap \mathrm{D}| \geq 2$. If every vertex in $\mathrm{V}-\mathrm{D}$ is $\mathrm{k}$ - dominated then $\mathrm{D}$ is called a $\mathrm{k}$ - dominating set. For details of on domination we refer to [4].

\section{Graph Operations}

A new graph can be built from the original graph with some special property. Graphs can be modified by deleting or adding elements using unary operation, or they can be built by combining multiple graphs using some binary operations.

In this section we study the effects on the domination number when the graph is modified by another graph by using the following operations.

1. Unary operations

2. Binary operations

Unary operations create a new graph from initial one. It can be classified into two categories

i. Elementary operations

ii. Advanced operations

Elementary operations create a new graph from on initial one by simple change, such as vertex deletion, an edge deletion or addition, edge contraction and edge subdivision.

Let $\mathrm{G}-\mathrm{v}$ ( respectively, $\mathrm{G}-\mathrm{e}$ ) denote the graph formed by removing vertex $\mathrm{v}$ ( respectively, removing an edge $\mathrm{e})$ from $\mathrm{G}$. Let $\mathrm{G}+\mathrm{e}$ denote the graph formed by adding an edge $\mathrm{e}$, where $\mathrm{e} \in \mathrm{E}(\overline{\mathrm{G}})$.

In [7], J. R. Carrington, F. Harary, and T. W. Haynes surveyed the results of characterizing the graphs G in the following six classes. They used the following acronyms to denote the following classes of graphs.

$\mathrm{C}$ - changing, $\mathrm{U}$ - unchanging, $\mathrm{V}$ - vertex, $\mathrm{E}$ - edge, $\mathrm{R}$ - removal, A - addition.

The six classes of graphs are listed below:

$\begin{array}{lll}\gamma(\mathrm{G}-\mathrm{v}) \neq \gamma(\mathrm{G}) \text { for all } \mathrm{v} \in \mathrm{V}(\mathrm{G}) & - & \mathrm{CVR}, \\ \gamma(\mathrm{G}-\mathrm{e}) \neq \gamma(\mathrm{G}) \text { for all } \mathrm{e} \in \mathrm{E}(\mathrm{G}) & - & \mathrm{CER}, \\ \gamma(\mathrm{G}+\mathrm{e}) \neq \gamma(\mathrm{G}) \text { for all } \mathrm{e} \in \mathrm{E}(\overline{\mathrm{G}}) & - & \mathrm{CEA}, \\ \gamma(\mathrm{G}-\mathrm{v})=\gamma(\mathrm{G}) \text { for all } \mathrm{v} \in \mathrm{V}(\mathrm{G}) & - & \mathrm{UVR}, \\ \gamma(\mathrm{G}-\mathrm{e})=\gamma(\mathrm{G}) \text { for all } \mathrm{e} \in \mathrm{E}(\mathrm{G}) & - & \mathrm{UER},\end{array}$


$\gamma(\mathrm{G}+\mathrm{e})=\gamma(\mathrm{G})$ for all $\mathrm{e} \in \mathrm{E}(\overline{\mathrm{G}}) \quad-\quad \mathrm{UEA}$.

It is useful to write the vertex set of a graph as a disjoint union of three sets according to how their removal affects $\gamma(\mathrm{G})$. Let $\mathrm{V}(\mathrm{G})=\mathrm{V}^{0} \cup \mathrm{V}^{+} \cup \mathrm{V}^{-}$for

$\mathrm{V}^{0}=\{\mathrm{v} \in \mathrm{V}: \gamma(\mathrm{G}-\mathrm{v})=\gamma(\mathrm{G})\}$

$\mathrm{V}^{+}=\{\mathrm{v} \in \mathrm{V}: \gamma(\mathrm{G}-\mathrm{v})>\gamma(\mathrm{G})\}$

$\mathrm{V}^{-}=\{\mathrm{v} \in \mathrm{V}: \gamma(\mathrm{G}-\mathrm{v})<\gamma(\mathrm{G})\}$.

Similarly, the edge set can be partitioned into

$\mathrm{E}^{0}=\{(\mathrm{uv}) \in \mathrm{E}(\mathrm{G}): \gamma(\mathrm{G}-(\mathrm{uv}))=\gamma(\mathrm{G})\}$

$\mathrm{E}^{+}=\{(\mathrm{uv}) \in \mathrm{E}(\mathrm{G}): \gamma(\mathrm{G}-(\mathrm{uv}))>\gamma(\mathrm{G})\}$.

Sticking on the characterization of J. R. Carrington et al. [7], we proceed with our survey in the following fashion

\section{Elementary Operations}

By using elementary operation we can generate a new graph from the original one by applying some small changes on initial graph. In this section we present some of the attractive results on elementary operations with the domination number like, CVR, CER, CEA, UVR, UER, UEA, edge contraction, and edge subdivision.

\section{Advanced Operations}

By using advanced operations we can create a new graph from the original graph by applying some complex changes on the initial one. In this section we provide some fascinating results on advanced operations with the domination number like, complement graph, line graph, and graph minors.

\section{Binary Operations}

By applying advanced operation we can generate a new graph from the two initial graphs. In this section we present some interesting results on advanced operations with the domination number like, cartesian product, tensor product of graphs, rooted product graph, and corona product of graphs.

The main aim of this paper is to present a survey of some possible results on the effect of graph operations on the domination number of a graph. The rest of the paper is ordered as follows.

i. Elementary operations

ii. Advanced operations

iii. Binary operations

\section{III.ELEMENTARY OPERATIONS}

\section{A. Changing Vertex Removal ( CVR)}

Removing a vertex can increase the domination number by more than one. For example, the center vertex of a wheel graph $\mathrm{W}_{\mathrm{n}}, \mathrm{n}>4$. But it can be decreasing by at most one. For example, an end vertex of a path $\mathrm{P}_{3}$. In general, if $\gamma(G-v) \neq \gamma(G)$ for all $v \in V(G)$, then $\gamma(G-v)=\gamma(G)-1$, for all $v \in V(G)$. A characterization of vertices whose removal increases the domination number as described by D. Bauer, F. Harary, J. Nieminen, C. L. Suffel [8].

\section{Theorem[8]}

A vertex $\mathrm{v} \in \mathrm{V}^{+}$if and only if

1. $v$ is not an isolate and is in every $\gamma$ - set of $G$ and

2. no subset $\mathrm{S} \subseteq \mathrm{N}-\mathrm{V}[\mathrm{v}]$ with cardinality $\gamma(\mathrm{G})$ dominates $\mathrm{G}-\mathrm{v}$.

Furthermore D. Bauer et al. have characterized vertices in trees satisfying the property [8].

\section{Theorem[8]}

For any tree $T$ with at least three vertices $\gamma(T-v)>\gamma(T)$ if and only if $v$ is in every $\gamma$ - set for $T$.

A slight modification of this result strengthens the result further to cut vertices [8].

\section{Theorem[8]}

If a cut vertex $v$ of $G$ is in every $\gamma$ - set for $G$, then $\gamma(G-v)>\gamma(G)$.

In [9], R. C. Brigham, P. Z. Chinn, R. D. Dutton, characterized the vertices in $\mathrm{V}^{-}$. They defined, vertex domination critical, or $\gamma$ - critical, or simply critical, if for any vertex $v$ of $G, \gamma(G-v)<\gamma(G)$. They have provided the following results. Note that the graphs in CVR are precisely the critical graphs.

\section{Theorem[9]}

A graph $\mathrm{G} \in \mathrm{CVR}$ if and only if each block of $\mathrm{G}$ is CVR. 

[9].

Using induction on the number of blocks the domination number of $\mathrm{G}$ is determined by R. C. Brigham et al.

\section{Theorem [9]}

Let $G$ have $b$ blocks $B_{1}, B_{2}, \ldots, B_{b}$. If $G \in C V R$, then $\gamma(G)=\left(\sum_{i=1}^{b} \gamma\left(B_{i}\right)\right)-b+1$.

In [10], E. Sampathkumar and P. S. Neeralagi characterized the vertices in $\mathrm{V}^{-}$.

\section{Theorem[10]}

A vertex $\mathrm{v}$ is in $\mathrm{V}^{-}$if and only if $\mathrm{pn}[\mathrm{v}, \mathrm{S}]=\{\mathrm{v}\}$ for some $\gamma-$ set $\mathrm{S}$ containing $\mathrm{v}$.

Once the necessary and sufficient conditions are known it is of interest to determine the bounds of the CVR graphs. We present few bounds of these graphs in terms of minimum degree and maximum degree, in terms of order, degree, and diameter.

\section{1) Bounds in CVR Graphs:}

R.C. Brigham et al. have provided the following bounds on CVR graphs in terms of its minimum degree and maximum degree [9].

\section{Theorem[9]}

If $\mathrm{G} \in \mathrm{CVR}$, then $\mathrm{n} \leq(\Delta(\mathrm{G})+1)(\gamma(\mathrm{G})-1)+1$.

Also they have provided the bounds on CVR graphs in terms of its edges, domination number and maximum degree.

\section{Theorem[9]}

If $\mathrm{G} \in \mathrm{CVR}$ with e edges, then $\mathrm{n} \leq \frac{(2 \mathrm{e}+3 \gamma(\mathrm{G})-\Delta(\mathrm{G}))}{3}$.

In 1995, J. Fulman, D. Hanson and G. MacGillivray, have discussed results on CVR graphs [11].

\section{Theorem [11]}

If a graph $\mathrm{G} \in \mathrm{CVR}$ has order $\mathrm{n}=(\Delta(\mathrm{G})+1)(\gamma(\mathrm{G})-1)+1$, then $\mathrm{G}$ is regular.

\section{Theorem [11]}

If a graph $\mathrm{G} \in \mathrm{CVR}$ and $\gamma(\mathrm{G}) \geq 2$, then $\operatorname{diam}(\mathrm{G}) \leq 2(\gamma(\mathrm{G})-1)$.

J. Fulman et al. characterized all CVR graphs with domination number 3 or 4 whose diameter achieves the upper bound in the above theorem [11].

\section{Theorem [11]}

1. A graph $G \in C V R$ with $\gamma(G)=3$ and $\operatorname{diam}(G)=4$ if and only if it has two blocks, each of which is CVR with $\gamma(G)=2$.

2. A graph $\mathrm{G} \in \mathrm{CVR}$ with $\gamma(\mathrm{G})=4$ and $\operatorname{diam}(\mathrm{G})=6$ if and only if it has three blocks, two of which are end blocks and all of which is CVR with $\gamma(\mathrm{G})=2$.

We now present NG type results related to CVR graphs

\section{Theorem[9]}

For any graph G, every pair of vertices has at least $\gamma(\overline{\mathrm{G}})-2$ common neighbors and, if $\gamma(\overline{\mathrm{G}}) \geq 3$, $\operatorname{diam}(\mathrm{G})$ $\leq 2$ and $\gamma(\mathrm{G}) \leq \mathrm{k}(\mathrm{G})$.

\section{Theorem[9]}

For any graph $\mathrm{G}$ with $\gamma(\overline{\mathrm{G}}) \geq 3, \gamma(\mathrm{G})+\gamma(\overline{\mathrm{G}}) \leq \mathrm{k}(\mathrm{G})+3$.

The following result applies to nontrivial CVR graphs, for which $\overline{\mathrm{G}}$ is also CVR.

\section{Corollary[9]}

For any graph $\mathrm{G}$ with $\gamma(\mathrm{G}) \geq 3$ and $\gamma(\overline{\mathrm{G}}) \geq 3, \gamma(\mathrm{G})+\gamma(\overline{\mathrm{G}}) \leq \min \{\mathrm{k}(\mathrm{G}), \mathrm{k}(\overline{\mathrm{G}})\}+3$.

Properties of vertices help in characterizing graphs that are not CVR. Results regarding this classification are discussed by various authors.

\section{Theorem[9]}

If $\mathrm{G}$ has a non isolated vertex $\mathrm{v}$ such that $\mathrm{N}(\mathrm{v})$ is complete, then $\mathrm{G} \notin \mathrm{CVR}$.

\section{Theorem [11]}

If there exists vertices $\mathrm{u}$ and $\mathrm{v}$ such that $\mathrm{N}[\mathrm{u}] \subseteq \mathrm{N}[\mathrm{v}]$, then $\mathrm{G} \notin \mathrm{CVR}$. 
In 1991, J. R. Carrington et al. determined the properties of $\mathrm{V}^{+}$and $\mathrm{V}^{-}$in CVR graphs [7].

\section{Theorem[7]}

For any graph $\mathrm{G}$,

1. If $\mathrm{v} \in \mathrm{V}^{+}$, then for every $\gamma$ - set $\mathrm{S}$ of $\mathrm{G}, \mathrm{v} \in \mathrm{S}$ and $\mathrm{pn}[\mathrm{v}, \mathrm{S}]$ contains at least two nonadjacent vertices,

2. If $\mathrm{x} \in \mathrm{V}^{+}$and $\mathrm{y} \in \mathrm{V}^{-}$, then $\mathrm{x}$ and $\mathrm{y}$ are not adjacent,

3. $\left|\mathrm{V}^{0}\right| \geq 2\left|\mathrm{~V}^{+}\right|$,

4. ( $\mathrm{G}) \neq \gamma(\mathrm{G}-\mathrm{v})$ for all $\mathrm{v} \in \mathrm{V}$ if and only if $\mathrm{V}=\mathrm{V}^{-}$and

5. If $\mathrm{v} \in \mathrm{V}^{-}$and $\mathrm{v}$ is not an isolate in $\mathrm{G}$, then there exists a $\gamma-$ set $\mathrm{S}$ of $\mathrm{G}$ such that $\mathrm{v} \notin \mathrm{S}$.

As a consequence of the above result, the following classification is further provided.

\section{Corollary[7]}

A graph $G \in C V R$ if and only if for each vertex $v \in V, p n[v, S]=\{v\}$ for some $\gamma-$ set $S$ containing $v$.

In [8], D. Bauer et al. have defined $\mu^{+}(\mathrm{G})$ and $\mu^{-}(\mathrm{G}) \cdot \mu^{+}(\mathrm{G})$ denotes the minimum number of vertices whose removal increases the domination number and $\mu^{-}(G)$ the corresponding number whose removal decreases the domination number. Some basic results on $\mu^{+}(\mathrm{G})$ and $\mu^{-}(\mathrm{G})$ are discussed below [8].

\section{Theorem [8]}

1. For any graph $\mathrm{G}, \mu^{-}(\mathrm{G})=1$ if and only if $\gamma(\mathrm{G})=0$.

2. For any graph $\mathrm{G}, \mu^{-}(\mathrm{G}) \leq \gamma(\mathrm{G})+1$.

3. For any graph $\mathrm{G}, \min \left\{\mu^{+}(\mathrm{G}), \mu^{-}(\mathrm{G})\right\} \leq \delta(\mathrm{G})+1$.

4. Let $\mathrm{T}$ be a tree. Then $\mu^{+}(\mathrm{T})=2$ if and only if there are vertices $\mathrm{u}$ and $\mathrm{v}$ such that

i. every $\gamma$ - set contains either $u$ or $v$.

ii. $\mathrm{v}$ is in every $\gamma-$ set for $\mathrm{T}-\mathrm{u}$ and $\mathrm{u}$ is in every $\gamma$ - set for $\mathrm{T}-\mathrm{v}$.

iii. no vertex is in every $\gamma$ - set.

\section{B. Changing Edge Removal ( CER)}

Removing an edge from any graph either leaves the domination number unchanged, for example Complete graph $K_{n}$, where $n \geq 3$, or increases it by exactly one, for example a star. In general, if $\gamma(G-e) \neq \gamma(G)$ for all $\mathrm{e} \in \mathrm{E}(\mathrm{G})$, then $\gamma(\mathrm{G}-\mathrm{e})=\gamma(\mathrm{G})+1$, for all $\mathrm{e} \in \mathrm{E}(\mathrm{G})$. Thus a graph for which the domination number changes when an arbitrary edge is removed has the property that $\gamma(\mathrm{G}-\mathrm{e})=\gamma(\mathrm{G})+1$, for every e $\in \mathrm{E}(\mathrm{G})$. The graphs in CER are called $\gamma^{+}-$critical graphs.

In [8], D. Bauer et al. characterized the following results in CER graphs. They have defined bondage number b ( G ), which they called the edge stability number, to be the minimum number of edges whose removal increases the domination number. The degree of an edge $(\mathrm{u} \mathrm{v})$ is defined by $\operatorname{deg}(\mathrm{u})+\operatorname{deg}(\mathrm{v})$ and $\delta^{\prime}(\mathrm{G})$ denotes the smallest degree of any edge.

\section{Theorem [8]}

A graph $\mathrm{G} \in \mathrm{CER}$ if and only if $\mathrm{G}$ is the union of stars $\mathrm{K}_{1, \mathrm{n}}$.

1) Bondage Number of Graphs:

In 1990, J. F. Fink, M. S. Jacobson, L. F. Kinch and J. Roberts [12] have provided the bondage number for different kind graphs like, complete graphs, cycle and paths.

\section{Theorem[12]}

1. The bondage number of the complete graph $K_{n}(n \geq 2)$ is $b\left(K_{n}\right)=\left\lceil\frac{n}{2}\right\rceil$.

2. The bondage number of the $\mathrm{n}-$ cycle is

$$
b\left(C_{n}\right)= \begin{cases}3 & \text { if } n \equiv 1(\bmod 3) \\ 2 & \text { otherwise. }\end{cases}
$$

3. The bondage number of the path of order $n,(n \geq 2)$ is given by

$$
b\left(P_{n}\right)= \begin{cases}2 & \text { if } n \equiv 1(\bmod 3) \\ 1 & \text { otherwise. }\end{cases}
$$

$\mathrm{Hu}$ and $\mathrm{Xu}$ [13], have obtained the bondage number for $(\mathrm{n}-3)$ regular graphs of order $\mathrm{n} \geq 4$. 


\section{Theorem[13]}

$\mathrm{b}(\mathrm{G})=\mathrm{n}-3$ for any $(\mathrm{n}-3)$ - regular graph of $\mathrm{G}$ of order $\mathrm{n} \geq 4$.

In 1997, U. Teschner has provided the bondage for general graphs [14].

\section{Theorem[14]}

If $\mathrm{G}$ is a nonempty graph with a unique minimum dominating set, then $\mathrm{b}(\mathrm{G})=1$.

Some principle results of bondage number for trees plays an important role in the study of bondage number. Here we present some results.

2) Bondage Number for Trees:

D. Bauer et al. proved that any tree has bondage number one or two [8].

\section{Theorem [8]}

If $\mathrm{T}$ is a tree with atleast two vertices, then $\mathrm{b}(\mathrm{T}) \leq 2$.

J. F. Fink et al. have characterized the bondage number of a more general class of graphs, specially, in trees. The final outcome of the results is discussed below [12].

\section{Theorem[12]}

1. If $\mathrm{T}$ is nontrivial tree, then $\mathrm{b}(\mathrm{T}) \leq 2$.

2. If any vertex of a tree $T$ is adjacent with two or more end - vertices, then $b(T)=1$.

3. If $\mathrm{F}$ is a forest, then $\mathrm{F}$ is an induced subgraph of a tree $\mathrm{S}$ with $\mathrm{b}(\mathrm{S})=1$ and a tree $\mathrm{T}$ with $\mathrm{b}(\mathrm{T})=2$.

U. Teschner has provided the necessary and sufficient condition for the trees having bondage number 1 [14].

\section{Theorem[14]}

A tree $\mathrm{T}$ has bondage number 1 if and only if $\mathrm{T}$ has a good vertex or an edge ( $\mathrm{x}$ y ) satisfying

1. $\mathrm{x}$ and $\mathrm{y}$ are neither good vertices nor bad vertices.

2. all neighbors of $\mathrm{x}$ and $\mathrm{y}$ ( except for $\mathrm{x}$ and $\mathrm{y}$ ) are bad.

3) Bounds on CER Graphs:

Bauer et al. have provided the following bound on CER graphs in terms of its maximum degree. Also they provided a bound in terms of minimum smallest degree [8].

\section{Theorem[8]}

If there exist at least one vertex $v \in V(G)$ such that $\gamma(G-v) \geq \gamma(G)$, then $b(G) \leq \Delta(G)$.

\section{Theorem[8]}

For any graph $\mathrm{G}, \mathrm{b}(\mathrm{G}) \leq \delta^{\prime}(\mathrm{G})-1$.

In [12], J. F. Fink et al. have established the bounds on the bondage number of a graph that are independent of the graph's structure.

1. If $\mathrm{G}$ is a connected graph of order $\mathrm{n} \geq 2$, then $\mathrm{b}(\mathrm{G}) \leq \mathrm{n}-1$.

2. If $\mathrm{G}$ is a nonempty graph, then $\mathrm{b}(\mathrm{G}) \leq \min \{\operatorname{deg}(\mathrm{u})+\operatorname{deg}(\mathrm{v})-1: \mathrm{u}$ and $\mathrm{v}$ are adjacent vertices $\}$.

3. If $\mathrm{G}$ is a nonempty connected graph, then $\mathrm{b}(\mathrm{G}) \leq \Delta(\mathrm{G})+\delta(\mathrm{G})-1$.

4. If $G$ is a nonempty graph with domination number $\gamma(G) \geq 2$, then $b(G) \leq(\gamma(G)-1) \Delta(G)+1$.

5. If $\mathrm{G}$ is a connected graph of order $\mathrm{n} \geq 2$, then $\mathrm{b}(\mathrm{G}) \leq \mathrm{n}-\gamma(\mathrm{G})+1$.

Finally they conclude with the following conjecture.

\section{Conjecture[12]}

If $\mathrm{G}$ is a nonempty graph, $\mathrm{b}(\mathrm{G}) \leq \Delta(\mathrm{G})+1$.

In 1994, B. L. Hartnell and D.F. Rall have provided some improved upper bounds for b ( G ) [15].

\section{Theorem [15]}

1. If $\mathrm{G}$ is a nonempty graph, then $\mathrm{b}(\mathrm{G}) \leq \min _{\mathrm{u} \in \mathrm{V}, \mathrm{x} \in \mathrm{N}(\mathrm{u})}\{\operatorname{deg}(\mathrm{u})+\mathrm{e}(\{\mathrm{x}\}, \mathrm{V}-\mathrm{N}[\mathrm{u}])\}$.

2. $\mathrm{b}(\mathrm{G}) \leq \operatorname{deg}(\mathrm{u})+\mathrm{e}(\{\mathrm{v}\}, \mathrm{V}-\mathrm{N}[\mathrm{u}])$ for every pair of non - adjacent vertices $\mathrm{u}$ and $\mathrm{v}$ in $\mathrm{G}$ for which $\gamma(\mathrm{G}+(\mathrm{u} v))=\gamma(\mathrm{G})$.

B. L. Hartnell et al. proved that, the bondage number of any graph with edge connectivity two will then necessarily satisfy that bound J. F. Fink's et al. conjectured in [12].

\section{Theorem[15]}

If $\mathrm{G}$ has edge connectivity $\mathrm{k}$, then, $\mathrm{b}(\mathrm{G}) \leq \Delta(\mathrm{G})+\mathrm{k}-1$. 
In [16], Yue - Li Wang has provided an improved upper bound for bondage number.

4) Bondage Number of NP - Hard Problem:

In 2012, Fu-Tao Hu and Jun-Ming Xu showed that the problem for determining the bondage numbers of general graphs is NP-hard. They stated the following decision problem [17].

\section{Bondage problem:}

Instance: A nonempty graph $\mathrm{G}$ and a positive integer $\mathrm{k}$.

Question: Is $\mathrm{b}(\mathrm{G}) \leq \mathrm{k}$ ?

Based on this problem, they have provided the following theorem.

\section{Theorem[17]}

The bondage problem is NP - hard.

In 2014, Fu - Tao Hu, Moo Young Sohn have proved that the bondage numbers of general graphs is NP-hard for the same decision problem [18].

\section{Theorem[18]}

The bondage problem is NP - hard even when restricted to bipartite graphs and $\mathrm{k}=1$.

Many contributions in CER graphs are related to determining bounds on bondage number. We present few results in this section.

\section{Changing Edge Addition ( CEA)}

Adding an edge to a graph cannot increase the domination number, for example, a star, and can decrease it by at most one, for example, adding an edge between an end vertex and a vertex of degree at least 2 in a corona. In general, if $\gamma(\mathrm{G}+\mathrm{e}) \neq \gamma(\mathrm{G})$ for all $\mathrm{e} \in \mathrm{E}(\overline{\mathrm{G}})$, then $\gamma(\mathrm{G}+\mathrm{e})=\gamma(\mathrm{G})-1$, for all, $\mathrm{e} \in \mathrm{E}(\overline{\mathrm{G}})$. In 1983, D. P. Sumner, P. Blitch have characterized the graphs in CEA and they called them as "edge domination critical graphs". The initial characterizations on CEA graphs were determined in [19].

\section{Theorem[19]}

1. A graph $G$ with $\gamma(G)=1$ is in CEA if and only if $G$ is $K_{n}$.

2. A graph $G$ with $\gamma(G)=2$ is in CEA if and only if $\bar{G}$ is the union of stars $K_{1, n}$.

In 1990, D. P. Sumner characterized CEA graphs [20].

\section{Theorem[20]}

$\mathrm{G} \in \mathrm{CEA}$ is a connected graph with $\gamma(\mathrm{G})=3$ if and only if $\mathrm{G}=\mathrm{A} \cup \mathrm{B}$ where either $\mathrm{A}$ is trivial and $\mathrm{B} \in$ CEA with $\gamma(G)=2$ or A is complete and B is a complete graph minus 1 factor.

As observed earlier, the maximum, minimum degree, order, diameter of a graph help in determining graph bounds. Established results on bounds of CEA graphs are presented in this subsection.

\section{1) Bounds on CEA Graphs:}

Let $d_{k}$ denote the number of vertices in $G$ of degree at most $k$. Bounds based on $d_{k}$ is provided in [19]

\section{Theorem[19]}

1. Let $\mathrm{G} \in \mathrm{CEA}$ be a connected graph with $\gamma(\mathrm{G})=3$. Then for $\mathrm{k} \geq 1, \mathrm{~d}_{\mathrm{k}} \leq 3 \mathrm{k}$.

2. Let $\mathrm{G} \in \mathrm{CEA}$ be a connected graph with $\gamma(\mathrm{G})=3$ and $|\mathrm{V}(\mathrm{G})|=\mathrm{n}$, with $\mathrm{n} \geq \mathrm{k}$, then $\mathrm{d}_{\mathrm{k}} \leq \mathrm{k}+1$.

3. If $\mathrm{G}$ is in CEA with $\gamma(\mathrm{G})=3$, then the diameter of $\mathrm{G}$ is at most 3 .

D. P. Sumner has provided an improved bound for CEA graphs [20].

\section{Theorem[20]}

1. Let $\mathrm{G} \in \mathrm{CEA}$ be a connected graph with $\gamma(\mathrm{G})=3$ and $|\mathrm{V}(\mathrm{G})|=\mathrm{n}$. Then $\mathrm{d}_{2} \leq 2$ for $\mathrm{n} \geq 2$.

2. Let $\mathrm{G} \in \mathrm{CEA}$ be a connected graph with $\gamma(\mathrm{G})=3$ and $|\mathrm{V}(\mathrm{G})|=\mathrm{n},|\mathrm{E}(\mathrm{G})|=\mathrm{m}$, then $\mathrm{m} \leq$ $\left(\begin{array}{c}\mathrm{n}-2 \\ 2\end{array}\right)$.

D. P. Sumner has describe a conjecture related to CEA graphs with $\gamma(\mathrm{G})=3$.

\section{Conjecture[20]}

Let $\mathrm{G} \in \mathrm{CEA}$ be a connected graph with $\gamma(\mathrm{G})=3$ and $|\mathrm{V}(\mathrm{G})|=\mathrm{n}$, then the number of edges in $\mathrm{G}$ is atleast $\min \left\{\left(\begin{array}{c}\mathrm{n}-2 \\ 2\end{array}\right)+\left(\begin{array}{l}\mathrm{k} \\ 2\end{array}\right)+\frac{\mathrm{k}-4}{2}\right\}$. 

[21].

In 1994, O. Favaron, D. Sumner, and E. Wojcicka have provided the results on CEA graphs with $\gamma(\mathrm{G})=\mathrm{k}$

\section{Theorem[21]}

If $\mathrm{G}$ is in CEA with $\gamma(\mathrm{G})=\mathrm{k}$, where $\mathrm{k} \geq 2$, then

1. the diameter of $\mathrm{G}$ is at most $2 \mathrm{k}-2$.

2. diameter of $\mathrm{G}$ is $\left[\frac{3 \mathrm{k}}{2}-1\right]$, for every $\mathrm{k}$.

\section{Theorem[21]}

If $\mathrm{G}$ is in CEA with $\gamma(\mathrm{G})=4$, then the diameter of $\mathrm{G}$ is at most 5 .

Characterizing hamiltonian graphs has always been a challenging problem for those interested in graph theory. Various techniques are devised and used for this purpose. Interestingly CEA graphs have been used in classifying hamiltonian graphs. Some classifications of interest is provided here.

2) CEA and Hamiltonian Graphs:

In 1990, E. Wojcicka showed that every connected, CEA graph with $\gamma(\mathrm{G})=3$ on more than 6 vertices has a hamiltonian path [22].

\section{Theorem[22]}

1. Let $\mathrm{G} \in \mathrm{CEA}$ be a connected graph, with $\gamma(\mathrm{G})=3$ and let $\mathrm{A}=\{\mathrm{x} \in \mathrm{V}(\mathrm{G}): \operatorname{deg}(\mathrm{x})=1\}$. Then $\mathrm{G}-\mathrm{A}$ is 2 connected.

2. If $\mathrm{G}$ is in CEA with $\gamma(\mathrm{G})=3$ on more than 6 vertices, then $\mathrm{G}$ has a hamiltonian path.

In the same paper, E. Wojcicka posed the following conjecture.

\section{Conjecture[22]}

Let $\mathrm{G} \in \mathrm{CEA}$ be a connected graph with $\gamma(\mathrm{G})=3$. Every graph $\mathrm{G}$ with no end vertex has a hamiltonian cycle. In 1991, Y. F. Xue and Z. Q. Chen have classified hamiltonian graphs related to minimum degree [23].

Several characterizations using minimum graph degree is credited by various authors.

\section{Theorem[23]}

If $\mathrm{G}$ is in CEA with $\gamma(\mathrm{G})=3$ and $\delta(\mathrm{G})=1$, then $\mathrm{G}-\mathrm{V}_{1}(\mathrm{G})$ has a hamiltonian cycle, where $\mathrm{V}_{1}(\mathrm{G})=$ $\{\mathrm{v} \in \mathrm{V}(\mathrm{G}) \mid \mathrm{d}(\mathrm{v})=1\}$

In 1999, F. Tian, B. Wei, L. Zhang have proved the following results with $\gamma(\mathrm{G})=\delta+2$ [24].

\section{Theorem[24]}

1. Every graph $\mathrm{G} \in \mathrm{CEA}$ with $\gamma(\mathrm{G})=3$ and $\delta \geq 2, \gamma(\mathrm{G})=\delta+2$ is hamiltonian.

2. Let $\mathrm{G} \in \mathrm{CEA}$ be a graph with $\gamma(\mathrm{G})=3$ and $\delta \geq 2, \gamma(\mathrm{G})=\delta+2$. Then $\mathrm{G}$ has only one vertex with degree $\delta$.

Let $\mathrm{P}(\mathrm{u}, \mathrm{v})$ be the length of the longest path connecting $\mathrm{u}$ and $\mathrm{v}$. A graph $\mathrm{G}$ of order $\mathrm{n}$ is said to be hamilton - connected if $d^{*}(G)=n-1$, where $d^{*}(G)=\min \{P(u, v) \mid u, v \in V(G)\}$. In 2002, Y. Chen, F. Tian and Y. Zhang have proved the following results on CEA graphs [25].

\section{Theorem[25]}

1. Let $\mathrm{G} \in \mathrm{CEA}$ be a 3 - connected graph with $\gamma(\mathrm{G})=3$ and $\delta \geq 2, \gamma(\mathrm{G})=\delta+2$. Then $\mathrm{G}$ is hamilton connected.

2. Let $\mathrm{G} \in \mathrm{CEA}$ be a connected graph with $\gamma(\mathrm{G})=3$ and $\gamma(\mathrm{G})=\delta+2$. Then $\mathrm{G}$ is hamilton connected if and only if $\delta \geq 3$.

\section{Theorem[19]}

1. Let $\mathrm{G}$ be a CEA connected graph with $\gamma(\mathrm{G})=3$. If $\mathrm{S}$ is an independent set with $|\mathrm{S}|=\mathrm{n}$ in $\mathrm{G}$, then there is some $\mathrm{x}$ in $\mathrm{S}$ with $\delta(\mathrm{x}) \geq \mathrm{n}-2$.

2. Every graph $\mathrm{G} \in \mathrm{CEA}$, with $\gamma(\mathrm{G})=3$ contains a triangle.

3. If $\mathrm{G}$ is in CEA with $\gamma(\mathrm{G})=3$, then no two end vertices of $\mathrm{G}$ have a common neighbor.

In general we have observed that the removal of a vertex from a graph may cause the domination number to grow dramatically. This does not happen in CEA graphs with $\gamma(\mathrm{G})=\mathrm{k}$ is established in [19 ].

\section{Theorem[19]}

If $\mathrm{G}$ is in CEA with $\gamma(\mathrm{G})=\mathrm{k}$, then for any vertex $\mathrm{v}$ of $\mathrm{G}, \gamma(\mathrm{G}-\mathrm{v}) \leq \mathrm{k}$. 
In 2008, V. Samodivkin has discussed results on CEA graphs relating $\gamma(\mathrm{G})$ and $\# \gamma(\mathrm{G})$, where $\# \gamma(\mathrm{G})$ denotes the number of all distinct minimum dominating sets of a graph.

Let $\mathrm{G}$ be a graph. An edge e $\in \mathrm{E}(\overline{\mathrm{G}})$ is $\# \gamma(\mathrm{G})$ - critical if $\# \gamma(\mathrm{G}+\mathrm{e})<\# \gamma(\mathrm{G})$. A graph $\mathrm{G}$ is $\# \gamma$ - edge - addition - critical if all edges of $\overline{\mathrm{G}}$ are $\# \gamma(\mathrm{G})$ - critical [26].

\section{Theorem[26]}

1. Let $x_{1}$ and $x_{2}$ be two distinct, nonadjacent and nonisolated vertices of a graph $G$. Then $\left(x_{1} x_{2}\right)$ is $\gamma$ $(G)$ - critical if and only if $\left(x_{1} x_{2}\right)$ is \# $\gamma(G)$ - critical.

2. Let $\mathrm{G}$ be a graph with no isolated vertex. Then $\mathrm{G}$ is $\gamma$ - edge - addition critical if and only if $\mathrm{G}$ is $\# \gamma$ - edge - addition - critical.

In 1990, J. Kok and C. M. Mynhart defined the reinforcement number $\mathrm{r}$ ( $\mathrm{G}$ ) to the smallest number of edges which must be added to $\mathrm{G}$ to decrease the domination number[27].

\section{Theorem[27]}

For any graph $\mathrm{G}, \gamma(\mathrm{G}) \leq \mathrm{n}-\Delta(\mathrm{G})-\mathrm{r}(\mathrm{G})+1$.

1. If $G$ is a graph with $\gamma(G) \geq 2$, then $r(G)=\mu(G)$.

2. If a graph $G$ has $\gamma(G)=2$, then $r(G)=n-\Delta(G)-1$.

In 2008, J. R.S. Blair, W. Goddard, S. T. Hedetniemi, S. Horton, P. Jones, and G. Kubicki, represented an O $\left(\mathrm{k}^{2} \mathrm{n}\right)$ dynamic programming algorithm for computing the maximum number of vertices that can be dominated using $\gamma(\mathrm{G})-\mathrm{k}$ dominators for a tree [28]. A corollary of this is a linear - time algorithm for computing the $\mathrm{k}-$ reinforcement number of a tree. In 2010, W. Ananchuen, N. Ananchuen, and R.E.L. Aldred have provided the structure of CEA graphs with $\gamma(\mathrm{G})=4$ and a cut vertex. Also they established some graphs of even order containing a perfect matching [29].

\section{Unchanging Vertex Removal ( UVR)}

As discussed earlier, vertex removal from a graph results in changing or unchanging the dominating set of a graph. We now present few results on UVR.

In 1983, D. Bauer et al. have proved that $\mathrm{V}^{0}$ is never empty for a tree and hence no tree is in CVR [8]. Hence the following theorem is true.

\section{Theorem[8]}

For any tree $\mathrm{T}$ with $\mathrm{n} \geq 2$, there exists a vertex $\mathrm{v} \in \mathrm{V}$ such that $\gamma(\mathrm{T}-\mathrm{v})=\gamma(\mathrm{T})$.

In 1979, H. B. Walikar and B. D. Acharya have provided the following theorem on UVR graphs [30].

\section{Theorem[30]}

A graph $\mathrm{G} \in \mathrm{UVR}$ if and only if $\mathrm{G}$ has no isolated vertices and for each vertex, either

1. There is an $\gamma$ - set $\mathrm{S}^{\prime}$ such that $\mathrm{v} \notin \mathrm{S}^{\prime}$ and for each $\gamma$ - set $\mathrm{S}$ such that $\mathrm{v} \in \mathrm{S}$, pn $[\mathrm{v}, \mathrm{S}]$ contains at least one vertex from $\mathrm{V}-\mathrm{S}$, or

2. $\mathrm{V}$ is in every $\gamma$ - set and there is a subset of $\gamma(\mathrm{G})$ vertices in $\mathrm{G}-\mathrm{N}[\mathrm{v}]$ that dominates $\mathrm{G}-\mathrm{v}$.

\section{E. Unchanging Edge Removal ( UER)}

The graphs for which the domination number is unchanged when an arbitrary edge is removed, that is $\gamma(\mathrm{G}-$ e $)=\gamma(\mathrm{G})$, for all $\mathrm{e} \in \mathrm{E}(\mathrm{G})$ are termed UER graphs. Unlike other kinds of operations, more results are dedicated to types of domination, rather than on the usual dominating set. In 1979, H. B. Walikar et al. have provided a classic characterization of UER graphs [30].

\section{Theorem[30]}

A graph $G \in$ UER if and only if for each $e=(u v) \in E(G)$, there is a $\gamma-$ set $S$ such that one of the following conditions is satisfied.

i. $\quad u, v \in S$.

ii. $\quad \mathrm{u}, \mathrm{v} \in \mathrm{V}-\mathrm{S}$.

iii. $\mathrm{u} \in \mathrm{S}$ and $\mathrm{v} \in \mathrm{V}-\mathrm{S}$ implies $|\mathrm{N}(\mathrm{v}) \cap \mathrm{S}| \geq 2$.

For a generic property $\mathrm{p}$, graphs with the minimum number of edges and having property $\mathrm{p}$ are called extremal graphs. The graph $G$ will be called edge domination insensitive if $\gamma(\mathrm{G})=\gamma(\mathrm{G}-\mathrm{e})$ for any edge e of $\mathrm{G}$ and it is denoted by $\mathrm{E}(\mathrm{n}, \gamma)$. The minimum number of edges in any $(\gamma, \mathrm{k})$ - insensitive graph of order $\mathrm{n}$ is denoted $\mathrm{E}_{\mathrm{k}}(\mathrm{n}, \gamma)$. In 1988, R. D. Dutton and R. C. Brigham have established the following results on extremal graphs and insensitive graphs [31]. 


\section{Theorem[31]}

1. Any extremal graph is bipartite with partite sets $V_{1}$ and $V_{2}$. Furthermore each vertex of $V_{2}$ has degree 2 .

2. Any extremal graph must have at least $4 \gamma(G)-4$ edges.

3. Extremal graphs exist for $\gamma(\mathrm{G}) \geq 2$ and $\mathrm{n} \geq 3 \gamma(\mathrm{G})-2$.

4. $E(n, \gamma)=2 n-2 \gamma(G)$ for $\gamma(G) \geq 2$ and $n \geq 3 \gamma(G)-2$ and is undefined otherwise.

5. If $n \geq 3 \gamma(G) \geq 6$, then $E(n, \gamma)=2 n-3 \gamma$.

In 1988, T. W. Haynes, R. C. Brigham and R. D. Dutton determined the value of $E_{2}$ ( n, 2 ) [32].

\section{Theorem[32]}

If $\mathrm{G}$ is a (2,2) - insensitive graph with $\mathrm{n} \geq 11$, then $\mathrm{E}_{2}(\mathrm{n}, 2)=\left\lfloor\frac{5 \mathrm{n}-10}{2}\right\rfloor$.

In 1992, B. L. Hartnell, D. F. Rall have provided a constructive tree characterization on $\mathrm{E}^{0}$ [33]. In 1993, T. W. Haynes, R. C. Brigham, R. D. Dutton have characterized ( $\gamma, \mathrm{k})$ - insensitive graph [34]. Results based on insensitive graphs is presented in this section.

\section{Theorem[34]}

1. For $\mathrm{k} \geq 1, \mathrm{E}_{\mathrm{k}}(\mathrm{n}, 1)=(2 \mathrm{k}+1)(\mathrm{n}-\mathrm{k}-1)$, if $\mathrm{n}>2 \mathrm{k}$ and is undefined if $\mathrm{n} \leq 2 \mathrm{k}$.

2. Let $\mathrm{k}+1 \leq \gamma \leq 2 \mathrm{k}$ and $\mathrm{n} \geq \gamma(\mathrm{k}+1)$. Then $\mathrm{E}_{\mathrm{k}}(\mathrm{n}, \gamma) \leq \frac{(\mathrm{k}+3) \mathrm{n}}{2}-\frac{(\mathrm{k}+3) \gamma-2 \mathrm{kr}-\mathrm{r}^{2}+\mathrm{r}}{2}$.

Let $\mathrm{N}_{\mathrm{i}}$ be the maximum number of vertices of degree at most $\mathrm{k}$ having atleast $\mathrm{i}$ common neighbors in a $(\gamma, \mathrm{k})$ - insensitive graph, $1 \leq \mathrm{i} \leq \mathrm{k}$. Let $\mathrm{f}(\mathrm{k})$ represent the number of vertices in $\mathrm{V}-\mathrm{D}$ having degree at most $\mathrm{k}$, where $\mathrm{D}$ is a dominating set.

\section{Theorem[34]}

Let $\mathrm{G}$ be a $(\gamma, \mathrm{k})$ - insensitive graph. Then, $\mathrm{N}_{\mathrm{k}} \leq 2$.

\section{Theorem[34]}

Let $\mathrm{G}$ be $\mathrm{a}(\gamma, \mathrm{k})$ - insensitive graph where $\mathrm{k} \geq 2, \gamma \geq 3$ and $\mathrm{n} \geq \gamma^{2}+2 \gamma+\mathrm{f}(\mathrm{k})$. Then

$\mathrm{E}_{\mathrm{k}}(\mathrm{n}, \gamma) \leq \frac{(\mathrm{k}+3) \mathrm{n}}{2}-\frac{2(\mathrm{k}+2) \gamma+(\mathrm{k}-1)\left(\gamma^{2}+\mathrm{f}(\mathrm{k})\right)}{2}$.

When $\mathrm{k}+1 \leq \gamma \leq 2 \mathrm{k}, \mathrm{E}_{\mathrm{k}}(\mathrm{n}, \gamma)$ is asymptotically equal to $(\mathrm{k}+3) \mathrm{n} / 2$ as $\mathrm{n}$ approaches infinity.

\section{F. Unchanging Edge Addition ( UEA)}

The graphs for which the domination number is unchanged when an arbitrary edge is added, that is $\gamma(\mathrm{G}+\mathrm{e})$ $=\gamma(\mathrm{G})$, for all, $\mathrm{e} \in \mathrm{E}(\overline{\mathrm{G}})$, were characterized in terms of their vertex sets by J. R. Carrington et al. [7].

\section{Theorem[7]}

A graph $\mathrm{G} \in \mathrm{UEA}$ if and only if $\mathrm{V}^{-}$is empty.

The other two elementary graph operations edge contraction and subdivision have contributed more to domination theory. Various graph theorists have investigated, explored properties related to these operations.

\section{G. Edge Contraction}

In graph theory, an edge contraction is an operation which removes an edge from a graph while simultaneously merging the two vertices that it previously joined. For a pair of vertices u, v of G, denote by G • uv the graph obtained by identifying $u$ and v. Let ( uv ) denote the identified vertex. So G . uv may be viewed as the graph obtained from $\mathrm{G}$ by deleting the vertices $\mathrm{v}$ and $\mathrm{u}$ and appending a new vertex, denoted by ( $\mathrm{uv}$ ), that is adjacent to all the vertices of $\mathrm{G}-\mathrm{v}-\mathrm{u}$ that were originally adjacent to either of $\mathrm{u}$ or $\mathrm{v}$ [35]. Identifying vertices cannot increase domination number and can decrease domination number by at most one or retain the same domination number.

\section{1) Dot Critical Graphs:}

In 2006 T. Burton and D.P. Sumner have defined domination dot - critical graphs. A graph is domination dot - critical if identifying any two adjacent vertices results in a graph with smaller domination number, that is $\gamma(\mathrm{G}$ . uv ) $<\gamma(G)$ for any two adjacent vertices $u$ and $v$. $G$ is dot - critical if and only if $\gamma(G$. uv ) $=\gamma(G)-1$ for any two adjacent vertices $u$ and $v$. $G$ is $k-\operatorname{dot}-$ critical means that $G$ is a dot critical graph with $\gamma(G)=k$. Let $\mathrm{G}^{\prime}$ be the set of critical vertices of $\mathrm{G}[35]$. 


\section{Theorem[35]}

1. Let $a, b \in V(G)$ for a graph $G$. Then $\gamma(G$. $a b)<\gamma(G)$ if and only if either there exists and MDS $S$ of $\mathrm{G}$ such that $\mathrm{a}, \mathrm{b} \in \mathrm{S}$ or at least one of $\mathrm{a}$ or $\mathrm{b}$ is critical in $\mathrm{G}$.

2. If $\mathrm{G}$ is any graph with $\gamma(\mathrm{G})=\mathrm{k} \geq 2$, then $\mathrm{G}$ is dot - critical if and only if every two adjacent non critical vertices belong to a common MDS.

3. Let $\mathrm{G}$ be any graph and $\mathrm{v} \in \mathrm{G}^{\prime}$. Then all of $\mathrm{N}[\mathrm{v}]$ is excellent.

4. For every graph $\mathrm{G}$, if $\mathrm{G}$ is dot critical, then $\mathrm{G}$ is excellent.

5. $\mathrm{G}$ is dot - critical if and only if each of its components is dot - critical.

6. A connected $3-\operatorname{dot}-$ critical graph $\mathrm{G}$ with $\mathrm{G}^{\prime}=\phi$ has a diameter of at most three.

A graph $\mathrm{G}$ is said to be spiked if $\mathrm{G}=\mathrm{H}$ o $\mathrm{K}_{1}$, the corona of a connected graph $\mathrm{H}$ with a single vertex.

\section{Theorem [ 35 ]}

Let $G$ be a graph with $n \geq 4$ vertices. Then $G$ is $2-\operatorname{dot}-$ critical if and only if $\bar{G}$ is not complete, but every component of $\overline{\mathrm{G}}$ is spiked or a complete graph $\mathrm{K}_{\mathrm{m}}, \mathrm{m} \geq 2$.

. A graph $\mathrm{G}$ is domination totally dot - critical ( just totally dot - critical ) if and only if $\gamma$ ( G . uv ) $=\gamma(\mathrm{G}$ ) - 1 for any two vertices u and v. In 2008, Zhao Chengye, Yang Yuansheng and Sun Linlin have extended this study on $\mathrm{k}$ - dot - critical graphs [36]. It was then followed by contributions by various authors.

\section{Theorem[36]}

1. There exists a totally $\mathrm{k}-\mathrm{dot}-$ critical graph with no critical vertices for any $\mathrm{k} \geq 4$.

2. A connected $4-\operatorname{dot}-$ critical graph $\mathrm{G}$ with $\mathrm{G}^{\prime}=\phi$ has a diameter of at most five.

In 2009, Xue - Gang Chen and Wai Chee Shiu have proved the following result [37].

\section{Theorem[37]}

$\mathrm{G}$ is a $1-$ connected $2 \mathrm{k}-\operatorname{dot}-$ critical graph with $\mathrm{G}^{\prime}=\phi$.

Let $\mathrm{G}$ be a $\mathrm{k}$ - connected non - complete graph ( where $\mathrm{k} \geq 2$ ). An edge of $\mathrm{G}$ is called $\mathrm{k}$ - contractible if its contraction results also in a $\mathrm{k}$ - connected graph. An edge that is not $\mathrm{k}$ - contractible is called a non contractible edge. If $\mathrm{G}$ does not have a $\mathrm{k}-$

contractible edge, then $\mathrm{G}$ is called contraction critical $\mathrm{k}$ - connected. In 2009, Tingting Li and Jianji Su have provided an improved bound for contraction critical 5 - connected graph [38].

\section{Theorem[38]}

Let $\mathrm{G}$ be a contraction critical 5 - connected graph. Then $\mathrm{G}$ has at least $\frac{3}{2}|\mathrm{G}|$ trivially noncontractible edges.

In 2013, M. Furuya characterized the connected $\mathrm{k}$ - dot - critical graphs with diameter of G [39].

\section{Theorem[39]}

1. The only $\mathrm{k}-$ dot - critical graph with diameter $3 \mathrm{k}-3$ is the path on $3 \mathrm{k}-2$ vertices.

2. Let $\mathrm{k} \geq 2$ and let $\mathrm{G}$ be a connected $\mathrm{k}$ - dot - critical graph. If $\mathrm{G}$ is 2 - connected, then $\operatorname{diam}(\mathrm{G}) \leq 2 \mathrm{k}$ -2 .

2) $\gamma$-Stable Graphs:

In 2013, M. Yamuna and K. Karthika have defined $\gamma$ - stable graphs. A graph G is said to be $\gamma$ - stable graph if $\gamma\left(G_{x y}\right)=\gamma(G)$, for all, $x, y \in V(G)$, $x$ is not adjacent to $y$. The following results were proved in [40].

\section{Theorem[40]}

1. A graph $\mathrm{G}$ is $\gamma$ - stable if and only if every $\gamma$ - set $\mathrm{D}$ of $\mathrm{G}$ is a clique.

2. A $\gamma$ - stable graph is a tree if $G$ has a unique $\gamma$ - set such that $\gamma(G)=2$.

3. If $\mathrm{G}$ is a $\gamma$ - stable tree, then every $\mathrm{v} \in \mathrm{V}-\mathrm{D}$ is a pendant vertex.

We recollect our very famous Kuratowski' $s$ theorem, perhaps the best ever result on planarity which states that "A graph $\mathrm{G}$ is planar if and only if it contains neither $\mathrm{K}_{5}$ nor $\mathrm{K}_{3,3}$ as a topological minor". So edge contraction is challenging, as it is used to identify planarity of graphs. Algorithms and results on characterizing planar graphs are developed, but it still remains as a challenging and tough problem, of course of interest to researchers. Similarly it is obvious that, maximal outerplanarity identification uses edge contraction. This section provides some interesting results relating edge contraction, planarity and graph domination. 


\section{Edge Contraction and Graph Planarity} graph [41].

In 2013, C. N. Campos and Y. Wakabayashi, have proved the interesting result on maximal outerplanar

\section{Theorem[41]}

1. Let $\mathrm{G}$ be a maximal outerplanar graph of order $\mathrm{n} \geq 4$. If $\mathrm{G}$ has $\mathrm{k}$ internal triangles, then $\mathrm{G}$ has $\mathrm{k}+2$ vertices of degree 2 .

2. Let $\mathrm{G}$ be a maximal outerplanar graph with $\mathrm{k}$ internal triangles and $\mathrm{n} \geq 3$ vertices. Then $\gamma(\mathrm{G})=\frac{\mathrm{n}+\mathrm{k}+2}{4}$.

In 2016, Zepeng Li, Enqiang Zhu, Zehui Shao, and Jin Xu, proved the following results on maximal outer planar graph by using edge contraction [42].

\section{Theorem[42]}

Let $G$ be an $n$ - vertex maximal outer planar graph. If $G$ has $k>0$ bad vertices, then $\gamma(G) \leq \frac{n+k}{4}$.

In 2014, a characterization of planar graphs when $\mathrm{G}$ and $\overline{\mathrm{G}}$ are $\gamma$ - stable graphs were provided in [43].

\section{Theorem[43]}

For any graph $\mathrm{G}$ such that $\gamma(\overline{\mathrm{G}})=\mathrm{k}, \overline{\mathrm{G}}$ is $\gamma$ - stable if and only if

1. there is atleast one set of $\mathrm{k}$ - independent vertices $\mathrm{S} \subseteq \mathrm{V}(\mathrm{G})$ such that there is no $\mathrm{v} \in \mathrm{V}-\mathrm{S}, \mathrm{v}$ adjacent to all vertices in $\mathrm{S}$.

2. for all $\mathrm{k}-$ non - independent vertices $\mathrm{S}$ in $\mathrm{G}$, there is atleast one $\mathrm{v} \in \mathrm{V}-\mathrm{S}$, $\mathrm{v}$ adjacent to all vertices in $\mathrm{S}$.

\section{Theorem[43 ]}

1. If $\mathrm{G}$ and $\overline{\mathrm{G}}$ are $\gamma$ - stable graphs such that $\gamma(\mathrm{G}) \leq 4$ and $\gamma(\overline{\mathrm{G}})=4$, then $\mathrm{G}$ is nonplanar.

2. If $\mathrm{G}$ and $\overline{\mathrm{G}}$ are $\gamma$ - stable graphs such that $\gamma(\mathrm{G}) \leq 4$ and $\gamma(\overline{\mathrm{G}})=3$, then $\mathrm{G}$ is nonplanar.

3) Domination Dot Stable Graphs:

A graph $\mathrm{G}$ is said to be domination dot stable ( DDS ) if $\gamma(\mathrm{G} . \mathrm{uv})=\gamma(\mathrm{G})$, for

all $\mathrm{u}, \mathrm{v} \in \mathrm{V}(\mathrm{G}), \mathrm{u} \perp \mathrm{v}$. A necessary and sufficient condition was proved in [44].

Theorem[44]

A graph $\mathrm{G}$ is DDS if and only if every $\gamma$ - set of $\mathrm{G}$ is an independent dominating set.

A method of generating a DDS graph from a graph G which is not DDS by using edge contraction is discussed in [45].

Theorem[45]

Let $\mathrm{G}$ be a graph which is not DDS. Then there exist a graph $\mathrm{G}^{\prime}$ generated by identifying the vertices of $\mathrm{G}$ such that $\mathrm{G}^{\prime}$ is DDS.

4) Domatic Dot Stable Graphs:

A graph $\mathrm{G}$ is said to be domatic dot stable ( dds ) if $\mathrm{d}$ ( $\mathrm{G}$. uv ) $=\mathrm{d}$ ( $\mathrm{G}$ ), for all $\mathrm{u}, \mathrm{v} \in \mathrm{V}$ ( $\mathrm{G}$ ) such that $\mathrm{u} \perp \mathrm{v}$ [46]. A necessary condition for a graph to be dds is provided in [ 46 ].

\section{Theorem[46]}

Let $\mathrm{G}$ be a graph and let $\mathrm{V}_{1}, \mathrm{~V}_{2}, \ldots, \mathrm{V}_{\mathrm{m}}$ be a domatic partition for $\mathrm{G}$ such that $\mathrm{d}(\mathrm{G})=\mathrm{m}$. If for $\mathrm{u} \in \mathrm{V}_{\mathrm{i}}, \mathrm{v} \in$ $V_{j}, i, j=1,2, \ldots, m$ and $i \neq j$ such that $u \perp v, d(G) \leq d(G$. uv ) if either

1. $\mathrm{V}_{\mathrm{i}} \cup\{\mathrm{v}\}$ is a dominating set for $\mathrm{G}$, and $\mathrm{V}_{\mathrm{j}}-\{\mathrm{v}\}$ is a dominating set for $\mathrm{G}$. or

2. $\mathrm{V}_{\mathrm{i}} \cup\{\mathrm{v}\}$ is a dominating set for $\mathrm{G}$ and if $\mathrm{V}_{\mathrm{j}}-\{\mathrm{v}\}$ is not a dominating set for $\mathrm{G}$ then there is some $\mathrm{w}$ $\in \mathrm{V}_{\mathrm{k}}$ such that $\mathrm{V}_{\mathrm{k}}-\{\mathrm{w}\}, \mathrm{k} \neq \mathrm{j}, \mathrm{k}=1,2, \ldots, \mathrm{m}$ is a dominating set and $\mathrm{V}_{\mathrm{j}}-\{\mathrm{v}\} \cup\{\mathrm{w}\}$ is a dominating set for $\mathrm{G}$,

for all $u, v \in V(G)$, then $G$ is dds.

\section{Theorem[46]}

Any tree with $n-$ vertices is dds where $n \geq 3$. 
A method for verifying some domination parameters like DDS and $\gamma$ - stable graphs using binary matrices are discussed in [47]. Also they provided a MATLAB code for the same [47].

\section{H. Subdivision}

A subdivision of a graph $\mathrm{G}$ is a graph resulting from the subdivision of edges in $\mathrm{G}$. The subdivision of some edge e with endpoints $\{\mathrm{u}, \mathrm{v}\}$ yields a graph containing one new vertex $\mathrm{w}$, with an edge set replacing e by two new edges, $\{\mathrm{u}, \mathrm{w}\}$ and $\{\mathrm{w}, \mathrm{v}\}$.

In [48], S. Arumugam has defined the domination subdivision number of a graph $\mathrm{G}$, denoted by $\operatorname{sd}_{\gamma}(\mathrm{G})$ to be the minimum number of edges that must be subdivided ( each edge in $G$ can be subdivided at most once ) in order to increase the domination number. S. Arumugam has proved the following result for trees.

\section{Theorem[48]}

For any tree $\mathrm{T}$ of order $\mathrm{n} \geq 3,1 \leq \operatorname{sd}_{\gamma}(\mathrm{T}) \leq 3$.

Although he stated that he has not been able to classify the trees for which $\operatorname{sd}_{\gamma}(T)=1, \operatorname{sd}_{\gamma}(T)=2$ or sd $\gamma$ $(\mathrm{T})=3$, S. Arumugam has stated the following conjecture.

\section{Conjecture[48]}

For any graph $\mathrm{G}$ or order $\mathrm{n} \geq 3,1 \leq \operatorname{sd}_{\gamma}(\mathrm{T}) \leq 3$.

In 2000, T.W. Haynes, S.M. Hedetniemi, and S.T. Hedetniemi, have provided an upper bound for the domination subdivision number for any graph $\mathrm{G}$ in terms of its degrees [49].

\section{Theorem[49]}

For any connected graph $\mathrm{G}$ and edge $(\mathrm{u} v)$, where $\operatorname{deg}(\mathrm{u}) \geq 2$ and $\operatorname{deg}(\mathrm{v}) \geq 2$,

$$
\operatorname{sd}_{\gamma}(\mathrm{G}) \leq \operatorname{deg}(\mathrm{u})+\operatorname{deg}(\mathrm{v})-1 \text {. }
$$

\section{Theorem[49]}

1. For any $\mathrm{k}$ - regular graph $\mathrm{G}$ where $\mathrm{k} \geq 2,1 \leq \mathrm{sd}_{\gamma}(\mathrm{G}) \leq 2 \mathrm{k}-1$.

2. For any cubic graph $\mathrm{G}, 1 \leq \mathrm{sd}_{\gamma}(\mathrm{G}) \leq 5$.

In 2001, T.W. Haynes, S.M. Hedetniemi, S.T. Hedetniemi, D. P. Jacobs, J. Knisely, and L. C. V. D. Merwe have presented the results on domination subdivision number [50].

\section{Theorem[50]}

1. If $\mathrm{G}$ has a strong support vertex, then $\operatorname{sd}_{\gamma}(\mathrm{G})=1$.

2. If $\mathrm{G}$ has adjacent support vertices, then $\operatorname{sd}_{\gamma}(\mathrm{G}) \leq 3$.

3. If $\mathrm{G}$ is a graph of order $\mathrm{n} \geq 3$ and $\gamma(\mathrm{G})=1$, then $\operatorname{sd}_{\gamma}(\mathrm{G})=1$.

4. If $\mathrm{G}$ is a connected graph of order $\mathrm{n} \geq 3$, then $\operatorname{sd}_{\gamma}(\mathrm{G}) \leq \gamma(\mathrm{G})+1$.

In 2002, A. Bhattacharya and G. R. Vijayakumar have proved the following bound [51].

\section{Theorem[51]}

For a connected graph of large order $n, \operatorname{sd}_{\gamma}(G) \leq 4 \sqrt{n} \ln n+5$.

In 2007, S. Benecke and C. M. Mynhardt have presented a simple characterization of trees with $\operatorname{sd}_{\gamma}(\mathrm{G})=1$ and a fast algorithm to determine whether a tree has this property [52].

\section{Theorem[52]}

For a tree $\mathrm{T}$ or order $\mathrm{n} \geq 3, \mathrm{sd}_{\gamma}(\mathrm{T})=1$ if and only if $\mathrm{T}$ has

1. a leaf $u \in N(T)$ or

2. an edge ( $\mathrm{x} y$ ) with $\mathrm{x}, \mathrm{y} \in \mathrm{N}(\mathrm{T})$.

A constructive characterization of trees such that $\mathrm{sd}_{\gamma}(\mathrm{T})$ is 3 is given by H. Aram, S. M. Sheikholeslami, and O. Favaron, in 2009 [53].

\section{Theorem[53]}

For a path on $\mathrm{n} \geq 3$ vertices,

$$
\operatorname{sd}_{\gamma}(G)= \begin{cases}1 & \text { if } n \equiv 0(\bmod 3) \\ 2 & \text { if } n \equiv 2(\bmod 3) \\ 3 & \text { if } n \equiv 1(\bmod 3) .\end{cases}
$$

For $\mathrm{t} \geq 1$, a subdivided star $\mathrm{SK}_{1, \mathrm{t}}$ is obtained by subdividing the $\mathrm{t}$ edges of a star $\mathrm{K}_{1, \mathrm{t}}$. H. Aram et al. have characterized the value of $\operatorname{sd}_{\gamma}(\mathrm{G})$ if $\mathrm{G}$ is a subdivided star. 


\section{Theorem[53]}

If the graph $\mathrm{G}$ has a strong support vertex then $\operatorname{sd}_{\gamma}(\mathrm{G})=1$ and if $\mathrm{G}$ is a subdivided star $\mathrm{SK}_{1, \mathrm{t}}$ with $\mathrm{t} \geq 2$ then $\operatorname{sd}_{\gamma}(\mathrm{G})=2$.

Finally H. Aram et al. characterized the trees whose domination subdivision number is 3 and a linear algorithm for recognizing them.

In 2010, B. Sharada and N. D. Sonar has given a constructive characterization of trees whose domination subdivision number is exactly two [54]. In 2011, S. Velammal and S. Arumugam, have obtained bounds for subdivision number [55].

\section{Theorem[55]}

1. Let $\mathrm{G}$ be a connected graph of order $\mathrm{n} \geq 2$. Then $\gamma(\mathrm{G}) \leq \operatorname{sd}_{\gamma}(\mathrm{G})$ and equality holds if and only if $\mathrm{G}=$ $\mathrm{K}_{2}$.

2. $\operatorname{sd}_{\gamma}\left(\mathrm{K}_{\mathrm{m}, \mathrm{n}}\right)= \begin{cases}2 & \text { if } 3 \leq \mathrm{m} \leq \mathrm{n} \\ 3 & \text { if } \mathrm{m}=2 \text { and } \mathrm{n} \geq 2 .\end{cases}$

3. Let $\mathrm{G}$ be a connected graph with $\gamma=\mathrm{n} / 2$. Then $\operatorname{sd}_{\gamma}(\mathrm{G}) \leq 3$.

\section{Theorem[55]}

For any tree of order $\mathrm{n} \geq 3, \mathrm{sd}_{\gamma}(\mathrm{T}) \leq 3$.

If there exists a vertex of a tree $T$ which is adjacent to at least two pendant vertices, then $\operatorname{sd}_{\gamma}(T)=1$ [55].

\section{1) Multisubdivision Number:}

In 2013, Magda Dettlaff, J. Raczek, and J. Topp have defined msd ( u v ) to be the minimum number of subdivisions of the edge ( $u v$ ) such that $\gamma(\mathrm{G})$ increases. Domination multisubdivision number of a graph $\mathrm{G}$, $\mathrm{m}>0$, denoted by $\operatorname{msd}(\mathrm{G})$ and it defined by $\operatorname{msd}(\mathrm{G})=\min \{\operatorname{msd}(\mathrm{uv}): \mathrm{uv} \in \mathrm{E}(\mathrm{G})\}$.

Magda Dettlaff et al. have provided the decision problem of domination subdivision and the multi subdivision problem stated as follows [56].

\section{Theorem[56]}

Domination Subdivision Number (DSN)

Instance: $\mathrm{Graph} G=(\mathrm{V}, \mathrm{E})$ and the domination number $\gamma(\mathrm{G})$.

Question: Is sd $(\mathrm{G})>1$ ?

\section{Theorem[56]}

Domination Subdivision Number is NP - complete even for bipartite graphs.

\section{Theorem[56]}

Domination Mulitsubdivision Number (DMN)

Instance: $\mathrm{Graph} G=(\mathrm{V}, \mathrm{E})$ and the domination number $\gamma(\mathrm{G})$.

Question: Is msd $(\mathrm{G})>1$ ?

\section{Observation[56]}

Let $\mathrm{G}$ be a graph. Then $\operatorname{sd}_{y}(\mathrm{G})=1$ if and only if $\operatorname{msd}(\mathrm{G})=1$.

\section{Theorem[56]}

1. Domination multisubdivision number is $\mathrm{NP}$ - complete even for bipartite graphs

2. If a graph $G$ has a strong support vertex, then $\operatorname{sd}_{\gamma}(G)=\operatorname{msd}(G)=1$.

3. For a connected graph $\mathrm{G}, 1 \leq \operatorname{msd}(\mathrm{G}) \leq 3$.

4. Let $\mathrm{T}$ be a tree with $\mathrm{n} \geq 3$. Then $\operatorname{sd}_{\gamma}(\mathrm{T})=\operatorname{msd}(\mathrm{T})$.

Magda Dettlaff et al. have provided a tree characterization with the domination multisubdivision number equal to 3 and 1 [56]. The graph obtained by subdividing an edge e from $\mathrm{G}$ is denoted by $\mathrm{G}_{\mathrm{e}}$. They defined $\mathrm{SR}-$ graph and ASR - graph as follows. A graph $G$ is $S R-$ graph if $\gamma(G-e)=\gamma\left(G_{e}\right)$ for any edge e of G. A graph $\mathrm{G}$ is an ASR - graph if $\gamma(\mathrm{G}-\mathrm{e}) \neq \gamma\left(\mathrm{G}_{\mathrm{e}}\right)$ for any edge e of $\mathrm{G}$. The set of all support vertices of $\mathrm{G}$ is denoted by Supp ( G ). In 2014, M. Lemanska, J. Tey, and R. Zuazua, characterized SR - tree and proved that ASR - graphs are $\gamma$ - insensitive [57].

\section{Remark[57]}

For any edge e of a graph $\mathrm{G}$ we have, $\gamma(\mathrm{G}) \leq \gamma\left(\mathrm{G}_{\mathrm{e}}\right) \leq \gamma(\mathrm{G})+1$. 


\section{Theorem[57]}

1. The path $P_{n}$ is an SR graph if and only if $n=3$ or $n \equiv 1(\bmod 3)$ for $n \geq 4$.

2. Let $n \geq 3$. If $n \equiv 1,2(\bmod 3)$, then the cycle $C_{n}$ is an SR - graph. Otherwise is an ASR - graph.

\section{Remark[57]}

1. Let $\mathrm{G}$ be a graph and $\mathrm{e}=(\mathrm{u} v)$ be an edge of $\mathrm{G}$ where $\{\mathrm{u}, \mathrm{v}\} \subseteq \operatorname{Supp}(\mathrm{G})$. Then $\gamma(\mathrm{G}-\mathrm{e})=\gamma(\mathrm{G})=\gamma$ $\left(G_{e}\right)$.

2. If $\gamma(G)=1$, then $\gamma\left(G_{e}\right)=2$ for any edge $e \in E(G)$.

\section{Theorem[57]}

1. Every graph is an induced subgraph of an $\mathrm{SR}-$ graph.

2. Every graph is an induced subgraph of an ASR - graph.

3. An ASR-graph has no bondage edges.

4. Every ASR - graph is $\gamma$ - insensitive.

2) Domination Subdivision Stable Graphs:

A graph $\mathrm{G}$ is said to be domination subdivision stable (DSS ), if the $\gamma$ - value of G does not change by subdividing any edge of $\mathrm{G}$. The graph obtained by subdividing any edge uv of a graph $\mathrm{G}$, is denoted by $\mathrm{G}_{\mathrm{sd}} \mathrm{uv}$. Let $\mathrm{w}$ be a vertex introduced by subdividing an edge $(\mathrm{u} v)$ and it is denote by $\mathrm{G}_{\mathrm{sd}} \mathrm{uv}=\mathrm{w}$. A necessary and sufficient condition for a graph G to be a DSS graph was proved in [58].

\section{Theorem[58]}

1. A graph G is DSS if and only if for every $u, v \in V(G)$, either $\exists$ a $\gamma$ - set containing $u$ and $v$ or $\exists$ a $\gamma$ set $\mathrm{D}$ such that

$$
\begin{aligned}
& \text { i. } P N[u, D]=\{v\} \\
& \text { ii. } v \text { is atleast } 2-\text { dominated. }
\end{aligned}
$$

2. For any graph $\mathrm{G}, \gamma\left(\mathrm{G}_{\text {sd }} \mathrm{uv}\right) \geq \gamma(\mathrm{G}) \forall \mathrm{e}=(\mathrm{uv}) \in \mathrm{E}(\mathrm{G})$.

In 2012 M. Yamuna and N. Sridharan, had defined a graph $G$ to be Just excellent ( JE ), if it to each $u \in V$ ( $\mathrm{G}$ ), there is a unique $\gamma$ - set of $\mathrm{G}$ containing $\mathrm{u}$ [59]. The domatic number of the subdivision graph of a just excellent graph was deteremined in [60].

\section{Theorem[60]}

If $G$ is JE, then $d\left(G_{s d}\right.$ uv $)=2$, if $d(G)=3$ and $d\left(G_{s d}\right.$ uv $) \leq 3$, if $d(G) \geq 4$.

3) Domatic Subdivision Stable Graphs:

A graph $\mathrm{G}$ is said to be domatic subdivision stable( dss ), if $\mathrm{d}(\mathrm{G})=\mathrm{d}\left(\mathrm{G}_{\mathrm{sd}} \mathrm{uv}\right)$, for all $\mathrm{u}, \mathrm{v} \in \mathrm{V}(\mathrm{G}), \mathrm{u} \perp \mathrm{v}$. The following results were proved in [61].

\section{Theorem[61]}

Let $\mathrm{G}$ be any graph. Then $\mathrm{d}\left(\mathrm{G}_{\mathrm{sd}} \mathrm{uv}\right) \leq 3$.

\section{Theorem[61]}

When $\mathrm{d}(\mathrm{G})=3, \mathrm{~d}\left(\mathrm{G}_{\mathrm{sd}} \mathrm{uv}\right)=3$ if and only if there is a partition $\mathrm{Z}=\left\{\mathrm{V}_{1}, V_{2}, V_{3}\right\}$ for $G$ such that

1. $\mathrm{V}_{1}$ and $\mathrm{V}_{2}$ are dominating sets for $\mathrm{G}$ such that $\mathrm{u} \in \mathrm{V}_{1}, \mathrm{v} \in \mathrm{V}_{2}$.

2. $\mathrm{v}$ is 2 - dominated with respect to $\mathrm{V}_{1}$.

3. $\mathrm{u}$ is $2-$ dominated with respect to $\mathrm{V}_{2}$.

4. $\mathrm{V}_{3}$ dominates atleast $\mathrm{G}-\{\mathrm{u}\}-\{\mathrm{v}\}$.

\section{Theorem[61]}

When $\mathrm{d}(\mathrm{G})=2, \mathrm{~d}\left(\mathrm{G}_{\mathrm{sd}} \mathrm{uv}\right)=3$ if and only if there is a domatic partition $\mathrm{d}(\mathrm{G})=\left|\left\{\mathrm{V}_{1}\right\},\left\{\mathrm{V}_{2}\right\}\right|, \mathrm{u} \in \mathrm{V}_{1}$, $\mathrm{v} \in \mathrm{V}_{2}$ such that

1. $\mathrm{v}$ is $2-$ dominated with respect to $\mathrm{V}_{1}$.

2. $\mathrm{V}_{2}=\mathrm{V}_{12} \cup \mathrm{V}_{22}$, where

a) $\mathrm{v} \in \mathrm{V}_{12}$, $\mathrm{u}$ is 2 - dominated with respect to $\mathrm{V}_{12}$.

b) $V_{22}$ does not dominate atleast one of $u$ or $v$, that is $V_{22}$ is a dominating set for $\mathrm{G}-\{\mathrm{u}\}-\{\mathrm{v}\}$. 


\section{IV.ADVANCED OPERATIONS}

Advanced operations create a new graph from one initial one, by a complex change. Due to the complexity of the operations, many operations like graph transpose, graph dual, graph rewriting, power of graph, medial graph, Y - $\Delta$ transform and mycielskian are explored less and yet to be used by researchers to relate them to domination. Researchers have contributed and related complement graph, line graph, and graph minors with dominating sets. Some interesting results on these operations are presented in this section.

\section{A. Complement Graph}

In graph theory, the complement or inverse of a graph $G$ is a graph $\overline{\mathrm{G}}$ on the same vertices such that two distinct vertices of $\overline{\mathrm{G}}$ are adjacent if and only if they are not adjacent in $\mathrm{G}$. When relating graph complement and domination number, most of the researchers have investigated NG type results. In 1956 Nordhaus and Gaddum have presented the relations between $G$ and $\bar{G}$ [62]. Any bound on the sum and/or the product of an invariant in a graph $\mathrm{G}$ and the same invariant in the complement $\overline{\mathrm{G}}$ of $\mathrm{G}$ is called a Nordhaus - Gaddum type relation or NG type relation. The relations of NG type for domination in graphs were proved by F. Jaeger and C. Payan in 1972, [63]. NG Type result is perhaps one classic result that most of the domination theorists have investigated.

\section{Theorem[63]}

For any graph $\mathrm{G}$ with at least two vertices, $3 \leq \gamma(\mathrm{G})+\gamma(\overline{\mathrm{G}}) \leq \mathrm{n}+1$ and $2 \leq \gamma(\mathrm{G}) \gamma(\overline{\mathrm{G}}) \leq \mathrm{n}$.

In 1976, M. Borowiecki has given the following results in terms of vertices [64].

\section{Theorem[64]}

1. For any graph $\mathrm{G}$ on $\mathrm{n} \geq 1$ vertices, $2 \leq \gamma(\mathrm{G})+\gamma(\overline{\mathrm{G}}) \leq \mathrm{n}+1$ and $1 \leq \gamma(\mathrm{G}) \cdot \gamma(\overline{\mathrm{G}}) \leq \mathrm{n}$.

2. If $\mathrm{G}$ is a graph on $\mathrm{n} \geq 2$ vertices, then $\gamma(\mathrm{G})+\gamma(\overline{\mathrm{G}})=3$ if and only if there exist two vertices $\mathrm{v}_{1}$ and $\mathrm{v}_{2}$ in $\mathrm{G}$ such that $\mathrm{d}\left(\mathrm{v}_{1}\right)=\mathrm{n}-1$ and $\mathrm{d}\left(\mathrm{v}_{2}\right)=1$ or $\mathrm{d}\left(\mathrm{v}_{1}\right)=\mathrm{n}-2$ and $\mathrm{d}\left(\mathrm{v}_{2}\right)=0$, where $\mathrm{d}(\mathrm{v})$ denotes the degree of the vertex $v$ in $G$.

3. For every positive integer $\mathrm{n}$, a graph $\mathrm{G}$ such that $|\mathrm{V}(\mathrm{G})|=\mathrm{n}, \gamma(\mathrm{G}), \gamma(\overline{\mathrm{G}})>4$ and $\gamma(\mathrm{G}) \gamma(\overline{\mathrm{G}})=$ $\mathrm{n}$ does not exist.

Characterizing extremal graphs was studied by different authors in several topics in domination. M. Borowiecki and E. J. Cockayne, S. T. Hedetniemi have characterized the following necessary and sufficient condition for sum of extremal graph and its complement [64] [65].

\section{Theorem[64][65]}

$\gamma(\mathrm{G})+\gamma(\overline{\mathrm{G}})=\mathrm{n}+1$ if and only if $\{\mathrm{G}, \overline{\mathrm{G}}\}=\left\{\mathrm{K}_{\mathrm{n}}, \overline{\mathrm{K}_{\mathrm{n}}}\right\}$, where $\mathrm{K}_{\mathrm{n}}$ is the complete graph on $\mathrm{n}$ vertices.

A partial result about the upper bound on the sum in terms of minimum degree was proved by $\mathrm{C}$. Payan in 1975 [66].

\section{Theorem[66]}

If $\mathrm{G}$ is a graph such that $\gamma(\overline{\mathrm{G}}) \geq 3$, then $\gamma(\mathrm{G})+\gamma(\overline{\mathrm{G}}) \leq \delta(\mathrm{G})+3$.

In 1985 R. Laskar and K. Peters improved the above bound for the case when both $\mathrm{G}$ and $\overline{\mathrm{G}}$ are connected [67].

\section{Theorem[67]}

When $\mathrm{G}$ and $\overline{\mathrm{G}}$ are both connected, $\gamma(\mathrm{G})+\gamma(\overline{\mathrm{G}}) \leq \mathrm{n}$ with equality if and only if $\mathrm{G}=\mathrm{P}_{4}$.

In 1995, J. P. Joseph and S. Arumugam have improved the upper bound for $\gamma(G)+\gamma(\bar{G})$ in graphs $G$ and $\bar{G}$, which does not contain isolated vertices [68].

\section{Theorem[68]}

If $G$ and $\overline{\mathrm{G}}$ have no isolated vertices, then $\gamma(\mathrm{G})+\gamma(\overline{\mathrm{G}}) \leq\left\lfloor\frac{n}{2}\right\rfloor+2$.

Moreover, if $\mathrm{n} \neq 9$, the bound is attained if and only if $\{\gamma(\mathrm{G}), \gamma(\overline{\mathrm{G}})\}=\left\{\left\lfloor\frac{n}{2}\right\rfloor, 2\right\}$. 
In 2005, J.E. Dunbar, T.W. Haynes, S.T. Hedetniemi have provided the necessary and sufficient condition for, $\gamma(\mathrm{G}), \gamma(\overline{\mathrm{G}})$, with respect to minimum degree [69].

\section{Theorem[69]}

If $\mathrm{G}$ and $\overline{\mathrm{G}}$ are connected graphs of order $\mathrm{n} \geq 23$ with $\delta(\mathrm{G}), \delta(\overline{\mathrm{G}}) \geq 2$, then $\gamma(\mathrm{G})+\gamma(\overline{\mathrm{G}})=\left\lfloor\frac{2 n}{5}\right\rfloor+$ 2 , if and only if $\{\gamma(\mathrm{G}), \gamma(\overline{\mathrm{G}})\}=\left\{\left\lfloor\frac{2 n}{5}\right\rfloor, 2\right\}$.

The following results were studied by L. Volkmann in 2011 [70].

\section{Theorem[70]}

1. If $\mathrm{G}$ is a graph of order $\mathrm{n} \neq 16$ with $\delta(\mathrm{G}), \delta(\overline{\mathrm{G}}) \geq 5$, then $\gamma(\mathrm{G})+\gamma(\overline{\mathrm{G}}) \leq\left\lfloor\frac{5 n}{14}\right\rfloor+2$. Moreover, if $\mathrm{n} \notin\{12,13, \ldots, 19\} \cup\{21,22,25\}$, equality holds if and only if $\{\gamma(\mathrm{G}), \gamma(\overline{\mathrm{G}})\}=$ $\left\{\left\lfloor\frac{5 n}{4}\right\rfloor, 2\right\}$.

2. If $\mathrm{G}$ is a graph of order $\mathrm{n}$ with $\delta(\mathrm{G}), \delta(\overline{\mathrm{G}}) \geq 6$, then $\gamma(\mathrm{G})+\gamma(\overline{\mathrm{G}}) \leq\left\lfloor\frac{6 n}{17}\right\rfloor+2$. Moreover, if $\mathrm{n}$ $\notin\{13, \ldots, 19\} \cup\{21,22,25\}$, equality holds if and only if $\{\gamma(\mathrm{G}), \gamma(\overline{\mathrm{G}})\}=\left\{\left\lfloor\frac{6 n}{17}\right\rfloor, 2\right\}$.

In1988, R.C. Brigham, P.Z. Chinn, R.D. Dutton provided an upper bounds in terms of connectivity, with $\gamma(\overline{\mathrm{G}}) \geq 3[71]$.

\section{Theorem[71]}

1. For any graph $\mathrm{G}$ with $\gamma(\overline{\mathrm{G}}) \geq 3, \gamma(\mathrm{G})+\gamma(\overline{\mathrm{G}}) \leq \mathrm{k}(\mathrm{G})+3$.

2. For any graph $\mathrm{G}$ with $\gamma(\mathrm{G}), \gamma(\overline{\mathrm{G}}) \geq 3, \gamma(\mathrm{G})+\gamma(\overline{\mathrm{G}}) \leq \min \{\mathrm{k}(\mathrm{G}), k(\overline{\mathrm{G}})\}+$

\section{B. Line Graph}

The line graph of an undirected graph $\mathrm{G}$ is another graph $\mathrm{L}(\mathrm{G})$ that represents the adjacencies between edges of G. A set of lines in a graph $\mathrm{G}$ is a line dominating set (written as LDS ), if every line not in S is adjacent to at least one line in S. N ( e ), the open neighbourhood of a line e is the set of all lines adjacent to e in G. In 1987 S. R. Jayaram has provided the following results in [72].

\section{Theorem[72]}

1. A LDS $\mathrm{S}$ is minimal if and only for each $\mathrm{e} \in \mathrm{S}$, one of the following two conditions holds

i. $\quad \mathrm{N}(\mathrm{e}) \cap \mathrm{S}=\phi$

ii. there exists a line $\mathrm{f} \in \mathrm{E}-\mathrm{S}$, such that $\mathrm{N}(\mathrm{f}) \cap \mathrm{S}=\{\mathrm{e}\}$.

2. If $\mathrm{G}$ is without isolated lines, then for every minimal LDS, $\mathrm{E}-\mathrm{S}$ is also a LDS.

C. Graph Minor

A minor of graph $\mathrm{G}$ is a graph which can be obtained from $\mathrm{G}$ by deleting vertices and deleting or contracting edges. Again, as discussed earlier whenever contraction comes into picture, the operation plays an important role in planarity and outerplanarity. Given a graph $\mathrm{H}$, a graph $\mathrm{G}$ is $\mathrm{H}$ - minor free if no minor of $\mathrm{G}$ is isomorphic to $\mathrm{H}$. It is well known that a simple graph $\mathrm{G}$ is outerplanar if and only $\mathrm{G}$ is both $\mathrm{K}_{4}-$ minor free and $\mathrm{K}_{2,3}-$ minor free. In 2013, C.N. Campos, Y. Wakabayashi provided the following theorem [73].

\section{Theorem [73]}

If $\mathrm{G}$ is a maximal outer planar graph of order $\mathrm{n} \geq 3$ having $\mathrm{k}$ vertices of degree 2 , then $\gamma(\mathrm{G}) \leq \frac{n+k}{4}$.

In 2015, Tingting Zhu, Baoyindureng Wu have discussed the following results [74]. 


\section{Theorem[74]}

Assume that $\mathrm{G}$ is a maximal $\mathrm{K}_{2,3}-$ minor free graph or a maximal $\mathrm{K}_{4}-$ minor free graph of order $\mathrm{n} \geq 3$. If $\mathrm{k}_{\mathrm{i}}$ is the number of vertices of degree $\mathrm{i}$ in $\mathrm{G}$ for $\mathrm{i}=1,2$, then $\gamma(G) \leq\left\lfloor\frac{n+2 k_{1}+k_{2}}{4}\right\rfloor$.

\section{Corollary[74]}

If $\mathrm{G}$ is a maximal $\mathrm{K}_{4}-$ minor free graph of order $\mathrm{n} \geq 3$ having $\mathrm{k}$ vertices of degree 2 , then $\gamma(G) \leq\left\lfloor\frac{n+k}{4}\right\rfloor$.

\section{Theorem[74]}

If $\mathrm{G}$ is a maximal $\mathrm{K}_{2,3}-$ minor free of order $\mathrm{n} \geq 2$ and size $\mathrm{m}$, then $\mathrm{m}=2 \mathrm{n}-2-\mathrm{t}$, where $\mathrm{t}$ is the number of blocks in $\mathrm{G}$ that are outerplanar.

\section{BINARY OPERATIONS}

Binary operations create a new graph from two initial ones $G_{1}=\left(V_{1}, E_{1}\right)$ and $G_{2}=\left(V_{2}, E_{2}\right)$. Binary operations are next level operations and hence little complicated to apply than the other kinds. Whenever the complexity of the operation increases, exploration is tough and relating them to domination is more difficult and challenging, but researchers have contributed a lot in relating all together. Some results are presented in this section. Due to the complexity of the binary operations, many operations like, graph union, graph intersection, graph join, Hajos construction are explored less and yet to be explored by researchers to relate them to domination.

Whenever it comes to binary operations, perhaps the most classic conjecture of graph theory is Vizing's Conjecture is related to Cartesian product. The related discussions are as follows, which ofcourse is familiar to most of the domination theorists

D. Graph Products

1) Cartesian Product:

Given two graphs $\mathrm{G}$ and $\mathrm{H}$, the Cartesian product $\mathrm{G} \square \mathrm{H}$ is define as follows:

1. $\mathrm{V}(\mathrm{G} \square \mathrm{H})=\mathrm{V}(\mathrm{G}) \times \mathrm{V}(\mathrm{H})$ and

2. $\left(\mathrm{u}_{1}, \mathrm{v}_{1}\right)\left(\mathrm{u}_{2}, \mathrm{v}_{2}\right) \in \mathrm{E}(\mathrm{G} \square \mathrm{H})$ if and only if $\mathrm{u}_{1}=\mathrm{u}_{2}$ and $\mathrm{v}_{1} \mathrm{v}_{2} \in \mathrm{E}(\mathrm{H})$, or $\mathrm{u}_{1} \mathrm{u}_{2} \in \mathrm{E}(\mathrm{G})$ and $\mathrm{v}_{1}=\mathrm{v}_{2}$.

\section{Vizing's Results on Domination}

\section{Vizing's Conjecture[75]}

For any two graphs $\mathrm{G}$ and $\mathrm{H}, \gamma(\mathrm{G} \square \mathrm{H}) \geq \gamma(\mathrm{G}) \gamma(\mathrm{H})$.

Also in [75], Vizing established the following bound.

\section{Theorem[75]}

$\gamma(\mathrm{G} \square \mathrm{H}) \leq \min \{\gamma(\mathrm{G})|\mathrm{H}|, \gamma(\mathrm{H})|\mathrm{G}|\}$.

The domination number of Cartesian product of two path and two cycles are determined in 1995, by S. Kalavzar, N. Seifter [76].

1. $\gamma\left(P_{2} \square P_{n}\right)=\left\lceil\frac{(n+1)}{2}\right\rceil$.

2. $\gamma\left(C_{3} \square C_{n}\right)=n-\left\lfloor\frac{n}{4}\right\rfloor, n \geq 4$.

3. $\gamma\left(C_{4} \square C_{n}\right)=n, n \geq 4$.

\section{Theorem [76]}

1. Let $\mathrm{X}=\mathrm{C}_{1} \square \mathrm{C}_{2} \square \ldots \square \mathrm{C}_{\mathrm{m}}$, where $\left|\mathrm{C}_{\mathrm{i}}\right|=2 \mathrm{~m}+1$ for each $\mathrm{C}_{\mathrm{i}}, 1 \leq \mathrm{i} \leq \mathrm{m}$. Then $\gamma(\mathrm{X})=(2 \mathrm{~m}+1)^{\mathrm{m}-1}$.

2. Let $X=C_{1} \square C_{2} \square \ldots \square C_{m}$ such that all $n_{k}=\left|C_{k}\right|, 1 \leq k \leq m$, are multiplies of $2 m+1$. Then $\gamma(X)=$

$$
\frac{\left(\prod_{k=1}^{m} n_{k}\right)}{(2 m+1)} \text {. }
$$

3. $\lim _{m \rightarrow \infty} \frac{\gamma\left(C_{m} \square C_{n}\right)}{m n}=\frac{1}{5}$. 
In 1999, R. Cherifi, S. Gravier, X. Lagraula, C. Payan, and I. Zighem posed the following conjecture [77].

\section{Conjecture[77]}

For sufficiently "large" $k$ and $n \gamma\left(P_{n} \square P_{k}\right)=\left\lfloor\frac{(k+2)(n+2)}{5}\right\rfloor-4$ holds.

In 2004, Liang Sun has proved the Vizing's conjecture with $\gamma(\mathrm{G})=3$ [78].

\section{Theorem[78]}

If $\gamma(\mathrm{G})=3$, then for any graph $\mathrm{H}, \gamma(\mathrm{G} \square \mathrm{H}) \geq \gamma(\mathrm{G}) \gamma(\mathrm{H})$.

In 2007, M.H. El-Zahar, S.M. Khamis, and Kh. M. Nazzal have provided the following theorem [79].

\section{Theorem[79]}

For any connected nontrivial graph $G$ and all $n \equiv 0$ or $2(\bmod 3) ; n \geq 3, \gamma\left(C_{n} \square G\right)>\gamma\left(C_{n}\right) \gamma(G)$.

A MDS D of $G$ excessive if there exists a vertex $\mathrm{v} \in \mathrm{D}$ such that $\mathrm{N}[\mathrm{D}-\{\mathrm{v}\}]=\mathrm{V}(\mathrm{G})-\{\mathrm{v}\}$. M.H. ElZahar posed the following conjecture.

\section{Conjecture[79]}

If $\mathrm{G}$ and $\mathrm{H}$ are two connected nontrivial graphs such that $\gamma(\mathrm{G} \square \mathrm{H})=\gamma(\mathrm{G}) \gamma(\mathrm{H})$, then each of $\mathrm{G}$ and $\mathrm{H}$ is either $\mathrm{K}_{2}$ or else has an excessive dominating set.

$\mathrm{G}$ is a minimum counterexample to Vizing's conjecture, if it has the smallest number of vertices among the counterexamples. In 2012, M. Pilipczuk, M, Pilipczuk and R. Skrekovski have given the following results and also proved that the minimum possible counterexample to Vizing's conjecture cannot have two neighboring vertices of degree two [80].

\section{Theorem[80]}

1. For any two graphs $\mathrm{G}$ and $\mathrm{H}, \gamma(\mathrm{G} \square \mathrm{H}) \geq \gamma(\mathrm{G}) \gamma(\mathrm{H}) / 2$.

2. If $\mathrm{G}$ has maximum degree $\Delta_{\mathrm{G}}$ and $\mathrm{H}$ has maximum degree $\Delta_{\mathrm{H}}$, then $\gamma(\mathrm{G} \square \mathrm{H}) \geq \frac{1}{2}\left(1+\frac{1}{\left(\Delta_{\mathrm{G}}^{2}-\Delta_{\mathrm{G}}+1\right)\left(\Delta_{\mathrm{H}}^{2}-\Delta_{\mathrm{H}}+1\right)}\right) \gamma(\mathrm{G}) \gamma(\mathrm{H})$.

3. If $G$ is a minimum counterexample to Vizing's conjecture, then $G$ does not contain two adjacent vertices of degree two.

Researchers have gone one step ahead in relating Cartesian product to CVR and CER graphs. In 2015, M. R. Chithra, A. Vijayakumar, have studied the results of Cartesian product They proved the following results with the notation that $\mathrm{V}\left(\mathrm{H}_{1}\right)=\left\{\mathrm{u}_{1}, \mathrm{u}_{2}, \ldots, \mathrm{u}_{\mathrm{n} 1}\right\}, \mathrm{V}\left(\mathrm{H}_{2}\right)=\left\{\mathrm{v}_{1}, \mathrm{v}_{2}, \ldots, \mathrm{v}_{\mathrm{n} 2}\right\}$.

\section{Theorem[81]}

Let $\mathrm{H}_{1} \square \mathrm{H}_{2}$ be a connected graph. Then

1. $\left(\mathrm{H}_{1} \square \mathrm{H}_{2}\right)=2$ if and only if $\mathrm{H}_{1}=\mathrm{K}_{2}$ and $\mathrm{H}_{2}$ is either a $\mathrm{C}_{4}$ or has a good vertex.

2. $\mathrm{H}_{1} \square \mathrm{H}_{2} \in \mathrm{CVR}$, with $\gamma\left(\mathrm{H}_{1} \square \mathrm{H}_{2}\right)=2$ if and only if $\mathrm{G}=\mathrm{C}_{4}$.

3. $\mathrm{H}_{1} \square \mathrm{H}_{2} \in \mathrm{CER}$, with $\gamma\left(\mathrm{H}_{1} \square \mathrm{H}_{2}\right)=2$ if and only if $\mathrm{H}_{1} \square \mathrm{H}_{2}=\mathrm{C}_{4}$.

4. $\mathrm{H}_{1} \square \mathrm{H}_{2} \in \mathrm{CVR}$, with $\gamma\left(\mathrm{H}_{1} \square \mathrm{H}_{2}\right)=3$ if and only if $\mathrm{H}_{1}=\mathrm{H}_{2}=\mathrm{K}_{3}$.

5. $\mathrm{H}_{1} \square \mathrm{H}_{2} \in \mathrm{CER}$, with $\gamma\left(\mathrm{H}_{1} \square \mathrm{H}_{2}\right)=3$ if and only if $\mathrm{H}_{1}=\mathrm{H}_{2}=\mathrm{K}_{3}$.

\section{Theorem[81]}

Let $\mathrm{P}_{\mathrm{n} 1} \square \mathrm{P}_{\mathrm{n} 2}$ be the Cartesian product of the path graphs on $\mathrm{n}_{1}$ and $\mathrm{n}_{2}$ vertices.

3. Then $P_{n 1} \square P_{n 2}$ is a vertex critical graph if and only if $n_{1}=n_{2}=2$.

4. If $\mathrm{n}_{1}, \mathrm{n}_{2} \geq 4$, then a minimum dominating set of $\mathrm{P}_{\mathrm{n}_{1}} \square \mathrm{P}_{\mathrm{n}_{2}}$ is disconnected.

\section{2) Tensor Product of Graphs:}

Given two graphs $\mathrm{G}$ and $\mathrm{H}$, the tensor product $\mathrm{G} \times \mathrm{H}$ is define as follows:

$\mathrm{V}(\mathrm{G} \square \mathrm{H})=\mathrm{V}(\mathrm{G}) \times \mathrm{V}(\mathrm{H})$ and

$\left(\mathrm{u}_{1}, \mathrm{v}_{1}\right)\left(\mathrm{u}_{2}, \mathrm{v}_{2}\right) \in \mathrm{E}(\mathrm{G} \square \mathrm{H})$ if and only if $\left(\mathrm{u}_{1} \mathrm{u}_{2}\right) \in \mathrm{E}(\mathrm{G})$ and $\left(\mathrm{v}_{1} \mathrm{v}_{2}\right) \in \mathrm{E}(\mathrm{H})$.

In 1995, S. Gravier and A. Khelladi provided the domination number of tensor product of graphs $\mathrm{G}$ and $\mathrm{H}$ [82]. 


\section{Theorems[82]}

1. For every $\mathrm{n} \geq 2$ and $\mathrm{k} \geq 4$, we have

$$
\gamma\left(P_{n} \times \overline{P_{k}}\right)= \begin{cases}n & \text { if } n \equiv 0(\bmod 4), \\ n+1 & \text { if } n \equiv 1 \operatorname{or} 3(\bmod 4), \\ n+2 & \text { if } n \equiv 2(\bmod 4) .\end{cases}
$$

2. For any $n>1$ and every graph $G$ we have, $\gamma\left(P_{n} \times G\right) \leq 2 \gamma(G)\left(\left\lfloor\frac{n}{4}\right\rfloor+1\right)$.

\section{Corollary[82]}

Let $\mathrm{n}$ and $\mathrm{k}$ be integers such that $\mathrm{n}>1$ and $\mathrm{k}>3$. For every path - hamiltonian graph $\mathrm{H}$ of order $\mathrm{n}$, we have $\gamma$ $\left(\mathrm{H} \times \overline{\mathrm{P}_{\mathrm{k}}}\right) \leq \mathrm{n}+2$.

For every path - hamiltonian graph $\mathrm{H}$ of order $\mathrm{n}$ and for every graph $\mathrm{G}$, we have $\gamma(\mathrm{H} \times \mathrm{G}) \leq 2 \gamma(\mathrm{G})\left(\left\lfloor\frac{\mathrm{n}}{4}\right\rfloor+1\right)$.

Finally S. Gravier et al. concluded that $\gamma\left(\mathrm{P}_{\mathrm{n}}\right) \gamma\left(\overline{\mathrm{P}_{k}}\right) \leq \gamma\left(\mathrm{P}_{\mathrm{n}} \times \overline{\mathrm{P}_{\mathrm{k}}}\right)$ and also provided the following conjecture for the domination number of the cross product of graphs.

\section{Conjecture[82]}

For all graphs $\mathrm{G}$ and $\mathrm{H}$, we have $\gamma(\mathrm{G} \times \mathrm{H}) \geq \gamma(\mathrm{G}) \gamma(\mathrm{H})$.

In 1999, R. Cherifi, S. Gravier, X. Lagraula, C. Payan, I. Zighem have studied the problem on tensor product graphs and determined the domination number of tensor product of two paths $P_{k}$ and $P_{n}$ [77].

\section{Theorem[77]}

Let $\mathrm{D}$ be a dominating set of a graph $\mathrm{G}=(\mathrm{V}, \mathrm{E})$. $\mathrm{D}$ is non - minimum if and only if there exists a pair $(\mathrm{X}$, $\mathrm{Y}$ ) of subsets of $\mathrm{V}$ such that $\mathrm{X} \subseteq \mathrm{D}$ and $\mathrm{Y} \subseteq \mathrm{V}$ with $\mathrm{N}[\mathrm{x}] \subseteq \mathrm{N}[\mathrm{Y}]$ and $|\mathrm{X}|>|\mathrm{Y}|$.

In 1999, R. Cherifi et al. have provided the domination number $\mathrm{P}_{\mathrm{k}} \times \mathrm{P}_{\mathrm{n}}$ for $\mathrm{k} \leq 8$. The results are summarized in Table $1[77]$.

TABLE 1

\begin{tabular}{|c|c|c|c|c|}
\hline $\mathrm{k}$ & $\mathrm{n}_{\mathrm{o}}$ & \multicolumn{3}{|c|}{$\gamma\left(P_{k} \times P_{n}\right)$ with $n \geq n_{o}$} \\
\hline 1 & 1 & $\mathrm{~N}$ & & \\
\hline 2 & 2 & $2\left\lceil\frac{\mathrm{n}}{3}\right\rceil$ & & \\
\hline 3 & 2 & $\begin{array}{l}\mathrm{N} \\
\mathrm{n}\end{array}$ & & if $n \equiv 0 \bmod 4$ \\
\hline 4 & 4 & $\begin{array}{l}\mathrm{n}+1 \\
\mathrm{n}+2 \\
5+6\end{array}$ & 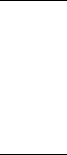 & $\begin{array}{l}\text { if } n \equiv 1 \text { or } 3 \bmod 4 \\
\text { if } n \equiv 2 \bmod 4 \\
\text { if } n=7\end{array}$ \\
\hline 5 & 5 & $\begin{array}{l}4\left\lceil\frac{\mathrm{n}}{3}\right\rceil \\
4\left\lceil\frac{\mathrm{n}}{3}\right\rceil\end{array}$ & $\begin{array}{r} \\
+2 \\
+\end{array}$ & $\begin{array}{l}\text { if } \mathrm{n} \equiv 1 \text { or } 2 \bmod 3 \\
\text { if } \mathrm{n} \equiv 0 \bmod 3\end{array}$ \\
\hline 6 & 6 & $\begin{array}{l}2\left\lceil\frac{4 n}{5}\right. \\
2\left\lceil\frac{9 n}{10}\right. \\
2\left\lceil\frac{9 n}{10}\right.\end{array}$ & $\begin{array}{l}+2 \\
+1\end{array}$ & $\begin{array}{l}\text { if } \mathrm{n} \equiv 0 \text { or } 2 \bmod 10 \\
\text { if } \mathrm{n} \equiv 1,3,5 \text { or } 7 \bmod 10\end{array}$ \\
\hline
\end{tabular}




\begin{tabular}{|l|l|ll|}
\hline 7 & 7 & $2\left[\frac{9 \mathrm{n}}{10}\right]$ & if $\mathrm{n} \equiv 4,6$ or $8 \bmod 10$ \\
& & $2\left[\frac{9 \mathrm{n}}{10}\right]-1$ & if $\mathrm{n} \equiv 9 \bmod 10$ \\
& & $6+8$ & if $\mathrm{n}=7$ \\
\hline 8 & 2 & $2 \mathrm{n}$ & if $\mathrm{n} \equiv 0 \bmod 4$ \\
& & $2 \mathrm{n}+2$ & if $\mathrm{n} \equiv 1,2 \operatorname{or} 3 \bmod 4$ \\
\hline
\end{tabular}

\section{E. Other Graph Products}

\section{1) Rooted Product Graph:}

A rooted graph is a graph with a designated vertex called the root. The rooted product of a graph $\mathrm{G}$ and a rooted graph $\mathrm{H}$ is defined as follows. Take $|\mathrm{V}(\mathrm{G})|$ copies of $\mathrm{H}$, and for every vertex $v_{i}$ of $G$, identify $v_{i}$ with the root vertex of the $\mathrm{i}^{\text {th }}$ copy of $\mathrm{H}$. Assume that $\mathrm{V}(\mathrm{G})=\left\{\mathrm{g}_{1}, \mathrm{~g}_{2}, \ldots, \mathrm{g}_{\mathrm{n}}\right\}, \mathrm{V}(\mathrm{H})=\left\{\mathrm{h}_{1}, \mathrm{~h}_{2}, \ldots, \mathrm{h}_{\mathrm{m}}\right\}$ and the root vertex of $\mathrm{H}$ is $\mathrm{h}_{1}$. The rooted product denoted by $\mathrm{G} \circ \mathrm{H}$ is defined as follows.

$\mathrm{G} \circ \mathrm{H}=(\mathrm{V}, \mathrm{E})$, where

$\mathrm{V}=\left\{\left(\mathrm{g}_{\mathrm{i}}, \mathrm{h}_{\mathrm{j}}\right), 1 \leq \mathrm{i} \leq \mathrm{n}, 1 \leq \mathrm{j} \leq \mathrm{m}\right\}$ and

$\mathrm{E}=\left\{\left(\left(\mathrm{g}_{\mathrm{i}}, \mathrm{h}_{1}\right),\left(\mathrm{g}_{\mathrm{k}}, \mathrm{h}_{1}\right)\right):\left(\mathrm{g}_{\mathrm{i}}, \mathrm{g}_{\mathrm{k}}\right) \in(\mathrm{E}(\mathrm{G})\} \cup \bigcup_{\mathrm{i}=1}^{\mathrm{n}}\left\{\left(\left(\mathrm{g}_{\mathrm{i}}, \mathrm{h}_{\mathrm{j}}\right),\left(\mathrm{g}_{\mathrm{i}}, \mathrm{h}_{\mathrm{k}}\right)\right):\left(\mathrm{h}_{\mathrm{i}}, \mathrm{h}_{\mathrm{k}}\right) \in \mathrm{E}(\mathrm{H})\right\}\right.$

The rooted product is a subgraph of the Cartesian product of the same two graphs.

The following results are proved by D. Kuziak, M. Lemanska, and I. G. Yero in [83].

\section{Theorem[83]}

1. Let $\mathrm{G}$ be a graph of order $\mathrm{n} \geq 2$ and let $\mathrm{H}$ be any graph with root $\mathrm{v}$ and at least two vertices. If $\mathrm{v}$ does not belong to any $\gamma(\mathrm{H})-$ set or $\mathrm{v}$ belongs to every $\gamma(\mathrm{H})-$ set, then $\gamma(\mathrm{G} \circ \mathrm{H})=\mathrm{n} \gamma(\mathrm{H})$.

2. Let $\mathrm{G}$ be a graph of order $\mathrm{n} \geq 2$. Then for any graph $\mathrm{H}$ with root $\mathrm{v}$ and at least two vertices, $\gamma(\mathrm{G} \circ \mathrm{H}) \in\{\mathrm{n} \gamma(\mathrm{H}), \mathrm{n}(\gamma(\mathrm{H}-1)+\gamma(\mathrm{G})\}$.

2) Corona Product of Graphs:

The corona $\mathrm{G} \circ \mathrm{H}$ of two graphs $\mathrm{G}$ and $\mathrm{H}$ is the graph obtained by taking one copy of $\mathrm{G}$ of order $\mathrm{n}$ and $\mathrm{n}$ copies of $\mathrm{H}$ and then joining the $\mathrm{i}^{\text {th }}$ vertex of $\mathrm{G}$ to every vertex in the $\mathrm{i}^{\text {th }}$ copy of $\mathrm{H}$. For every $\mathrm{v} \in \mathrm{V}(\mathrm{G})$, denote by $\mathrm{H}^{\mathrm{v}}$ the copy $\mathrm{H}$ whose vertices are attached one by one to the vertex $\mathrm{v}$. Subsequently denote by $\mathrm{v}+\mathrm{H}^{\mathrm{v}}$ the subgraph of the corona $\mathrm{G} \circ \mathrm{H}$ corresponding to the join $\langle\{\mathrm{v}\}\rangle+\mathrm{H}^{\mathrm{v}}, \mathrm{v} \in \mathrm{V}(\mathrm{G})$. In 2011, Carmelito E. Go, S. R. Canoy have provided the following results [84].

\section{Theorem[84]}

1. Let $\mathrm{G}$ be a connected graph of order $\mathrm{m}$ and let $\mathrm{H}$ be any graph of order $\mathrm{n}$. Then $\mathrm{C} \subseteq \mathrm{V}(\mathrm{G} \circ \mathrm{H})$ is a dominating set in $\mathrm{G} \circ \mathrm{H}$ if and only if $\mathrm{V}\left(\mathrm{v}+\mathrm{H}^{\mathrm{v}}\right) \cap \mathrm{C}$ is a dominating set of $\mathrm{v}+\mathrm{H}^{\mathrm{v}}$ for every $\mathrm{v} \in \mathrm{V}$ ( $G$ ).

2. Let $\mathrm{G}$ be a connected graph of order $m$ and let $H$ be any graph of order $n$. Then $\gamma(G \circ H)=m$.

\section{VI.SUMMARY AND CONCLUSION}

In this paper we presented some selective results on graph operations with its consequences on the domination number of a graph. We established some results on elementary operation, advanced operation and binary operation. These results are describing the bond between the normal graph operation and the domination number. We also have provided the possible bounds of the different kind of graph operation with respect to domination number. We presented some results of graph operation on domination number in different kind of graphs like, regular graphs, cubic graphs, complement graph, bipartite graph, complete bipartite graph, planar graph, outerplanar graph, hamiltonian graph and extremal graph.

Domination theory is now well established and is spreading its contributions to different domains in graph theory and graph applications. Graph operations favour in solving graph conjectures, and has contribute more in characterizing graph planarity and hamiltoninan graphs, as has been understood from this brief survey. The 
influence of these graph operations on other kinds of dominating sets have also enormous contributed in this regard and it has a long way to go in future, breaking conjectures and solving various problems.

\section{REFERENCES}

[1] C.Berge, "Theory of Graphs and its Applications", Methuen, London; 1962.

[2] O. Ore, "Theory of Graphs", Amer. Math. Soc. Colloq. Publ., 38 , ( Amer. Math. Soc., Providence, RI ), 1962.

[3] E. J. Cockayne, S. T. Hedetniemi, "Towards a Theory of Domination in Graphs", Networks, 7, pp. 247 - 261, 1977.

[4] T.W. Haynes, S.T. Hedetniemi, P. J. Slater, "Fundamentals of Domination in Graphs", Marcel Dekker, Inc., New York; 1998.

[5] T. W. Haynes, S.T. Hedetniemi, P.J. Slater, "Domination in Graphs: Advanced Topics", Marcel Dekker, Inc., New York, 1998.

[6] F. Harary, "Graph Theory", Addison Wesley/ Narosa Publishing House Reprint 1988, $10^{\text {th }}$ reprint; 2001.

[7] J. R. Carrington, F. Harary, T. W. Haynes, "Changing and Unchanging the Domination Number of a Graph", Journal of Combinatorial Mathematics and Combinatorial Computing, 9, $57-63,1991$.

[8] D. Bauer F. Harary, J. Nieminen, C. L. Suffel, "Domination Alteration Sets in Graphs", Discrete Mathematics, 47, 153 - 161, 1983.

[9] R.C. Brigham, P. Z. Chinn, R. D. Dutton, "Vertex Domination - Critical Graphs", Networks, 18, 173 - 179, 1988.

[10] E. Sampathkumar, P. S. Neeralagi, "Domination and Neighbourhood Critical, Fixed, Free and Totally Free Points", Sankhya ( Special Volume ), 54, $403-407,1992$.

[11] J. Fulman, D. Hanson, G. MacGillivray, "Vertex Domination - Critical Graphs", Networks, 25, 41 - 43, 1995.

[12] J. F. Fink, M. S. Jacobson, L. F. Kinch, J. Roberts, “The Bondage Number of a Graph”, Discrete Mathematics, 86, pp. 47 - 57, 1990.

[13] arxiv.org/pdf/1109.3931

[14] U. Teschner, "New Results about the Bondage Number of a Graph”, Discrete Mathematics, 171 (1-3 ), 249 - 259, 1997.

[15] B. L. Hartnell, D. F. Rall, "Bounds on the Bondage Number of a Graph", Discrete Mathematics, 128, 173 - 177, 1994.

[16] Yue - Li Wang, "On the Bondage Number of a Graph", Discrete Mathematics, 159, 291 - 294, 1996.

[17] Fu-Tao Hu, Jun-Ming Xu, "On the Complexity of the Bondage and Reinforcement Problems", Journal of Complexity, 28 ( 2 ), 192 201, 2012.

[18] Fu - Tao Hu, Moo Young Sohn, "The Algorithmic Complexity of Bondage and Reinforcement Problems in Bipartite Graphs", Theoretical Computer Science, 535, 46 - 53, 2014.

[19] D. P. Sumner, P. Blitch P, "Domination Critical Graphs", Journal of Combinatorial Theory, Series B, 34, 65 - 76, 1983.

[20] D. P. Sumner, "Critical Concepts in Domination", Discrete Mathematics, 86, 33 - 46, 1990.

[21] O. Favaron, D. Sumner, E. Wojcicka, "The Diameter of Domination k - Critical Graphs", J. Graph Theory, 18 ( 7 ), 723 - 734, 1994.

[22] E. Wojcicka, "Hamiltonian Properties of Domination - Critical Graphs", J. Graph Theory, 14 ( 2 ), 205 - 215, 1990

[23] Y. F. Xue, Z. Q. Chen, "Hamilton Cycles in Domination - Critical Graphs", J. Nanjing University ( Natural Science edition, Special Issue on Graph Theory ), 27, $58-62,1991$.

[24] F. Tian, B. Wei, L. Zhang. "Hamiltonicity in 3 Domination - Critical Graphs with $\alpha=\delta+2$ ", Discrete Applied Mathematics, 92, $57-$ $70,1999$.

[25] Y. Chen, F. Tian, Y. Zhang, "Hamilton - Connectivity of 3 - Domination Critical Graphs with $\alpha=\delta+2$ ", Europ. J. Combinatorics, 23 , $777-784,2002$

[26] V. Samodivkin, "Changing of the Number of Minimum Dominating Sets after Edge Addition: Critical Edges", AKCE J. Graphs. Combin., 5 ( 1 ), $29-33,2008$.

[27] J. Kok, C. M. Mynhardt, "Reinforcement in Graphs", Congr. Numer., 79, 225 - 231, 1990.

[28] J. R. S. Blair, W. Goddard, S. T. Hedetniemi, S. Horton, P. Jones, G. Kubicki, "On Domination and Reinforcement numbers in Trees", Discrete Mathematics, 308, $1165-1175,2008$.

[29] W. Ananchuen, N. Ananchuen, R.E.L. Aldred, "The Structure of 4 - $\gamma$ - Critical Graphs with a Cut Vertex", Discrete Mathematics, 310, $2404-2414,2010$.

[30] H. B. Walikar, B. D. Acharya, "Domination Critical Graphs", Nat. Acad. Sci. Lett., 2, 70 - 72, 1979.

[31] R. D. Dutton, R. C. Brigham, "An Extremal Problem for Edge Domination Insensitive Graphs", Discrete Applied Mathematics, 20 , $113-125,1988$

[32] T. W. Haynes, R. C. Brigham, R. D. Dutton, "Extremal 2 - 2 Insensitive Graphs", Congr. Numer., 67, 158 - 166, 1988.

[33] B. L. Hartnell, D. F. Rall, "A Characterization of Trees in which no Edge is Essential to the Domination Number", ARS Combinatoria., $33,65-76,1992$.

[34] T. W. Haynes, R. C. Brigham, R. D. Dutton, "Extremal Graphs Domination Insensitive to the Removal of k - Edges", Discrete Applied Mathematics, 44, 295 - 304, 1993.

[35] T. Burton, D. P. Sumner, "Domination Dot - Critical Graphs", Discrete Mathematics, 306, 11- 18, 2006

[36] Zhao Chengye, Yang Yuansheng, Sun Linlin, "Domination Dot - Critical Graphs with no Critical Vertices", Discrete Mathematics, $308,3241-3248,2008$.

[37] Xue - gang Chen and Wai Chee Shiu. "A Note on the Domination Dot - Critical Graphs", Discrete Applied Mathematics, 157, 3743 $3745,2009$.

[38] Tingting Li, Jianji su, "A New Lower Bound on the Number of Trivially Noncontractible Edges in Contraction Critical 5 - Connected Graphs", Discrete Mathematics, 309, 2870-2876, 2009.

[39] M. Furuya, "Upper Bounds on the Diameter of Domination Dot - Critical Graphs with Given Connectivity", Discrete Applied Mathematics, 161, 2420-2426, 2013.

[40] M. Yamuna, K. Karthika. “ $\gamma$ - Stable Tree”, International Journal of Pure and Applied Mathematics, 87 ( 3 ), 453 - 458, 2013.

[41] C. N. Campos, Y. Wakabayashi, "On Dominating Sets of Maximal Outerplanar Graphs", Discrete Applied Mathematics, 161, 330 $335,2013$.

[42] Zepeng Li, Enqiang Zhu, Zehui Shao, Jin Xu. "On Dominating Sets of Maximal Outerplanar and Planar Graphs", Discrete Applied Mathematics, 198,164-169, 2016.

[43] M. Yamuna, K. Karthika, "Planar Graph Characterization using $\gamma$ - Stable Graphs", WSEAS Transactions on Mathematics, 13, 493 504, 2014.

[44] M. Yamuna, K. Karthika, "Excellent - Domination Dot Stable Graphs", International Journal of Engineering Science Advanced Computing and Bio - Technology, 2 ( 4 ), 209 - 216, 2011.

[45] M. Yamuna, K. Karthika, "Generating DDS Graphs by Edge Contraction”, International Journal of Advanced Scientific and Technical Research, 4 ( 2 ), $348-354,2012$.

[46] M. Yamuna, K. Karthika, "Domatic Dot Stable Graphs", Journal of Current Engineering Research, 1 ( 3 ), 16 - 19, 2012.

[47] M. Yamuna, K. Karthika, "Domination Parameter Characterization using Matrix Representation", Indian Journal of Science and Technology, 8 ( 15 ): 1-9, 2015.

[48] Arumugam S. Private Communication, June 2000. 
[49] T.W. Haynes, S.M. Hedetniemi, S.T. Hedetniemi, "Domination and Independence Subdivision Numbers of Graphs", Discussiones Mathematicae Graph Theory, 20, $271-280,2000$.

[50] T.W. Haynes, S.M. Hedetniemi, S.T. Hedetniemi, D. P. Jacobs, J. Knisely, L. C. V. D. Merwe, "Domination Subdivision Number", Discussiones Mathematicae Graph Theory, 21, 239-253, 2001.

[51] A. Bhattacharya, G. R. Vijayakumar, "Effect of Edge - Subdivision on Vertex - Domination in a Graph", Discussiones Mathematicae Graph Theory, 22, $335-347,2002$.

[52] ajc.maths.uq.edu.au/pdf/42/ajc_v42_p201.pdf.

[53] H. Aram, S. M. Sheikholeslami, O. Favaron, "Domination Subdivision Numbers of Trees", Discrete Mathematics, 309, 622 - 628, 2009.

[54] B. Sharada, N. D. Sonar, "On the Domination Subdivision Numbers of Trees", Australasian Journal of Combinatorics, 46, 233 - 239, 2010.

[55] S. Velammal, S. Arumugam. "Domination and Subdivision in Graphs", Indian Journal of Applied Research, 1( 3 ), 180 - 183, 2011.

[56] arxiv.org/pdf/1310.1345v2.pdf

[57] arxiv.org/abs/1409.7508

[58] M. Yamuna, K. Karthika, "Domination Subdivision Stable Graphs", International Journal of Mathematical Archive, $3(4$ ), 1467 $1471,2012$.

[59] M. Yamuna, N. Sridharan, "Just Excellent Graphs", International Journal of Engineering Science. Advance Computing and Bio Technology, 1(3), $129-136,2010$

[60] M. Yamuna, K. Karthika, "Domatic Number of Just Excellent Subdivision Graphs", Elixir Applied Mathematics, 53, 11833 - 11835 , 2012.

[61] M. Yamuna, K. Karthika, "Domatic Subdivision Stable Graphs", Global Journal of Pure and Applied Mathematics, 9 ( 2 ), 137-142, 2013.

[62] E. A. Nordhaus, J. W. Gaddum, “On Complementary graphs", Amer. Math. Monthly, 63, 175 - 177, 1956.

[63] F. Jaeger, C. Payan, "Relations du type Nordhaus-Gaddum pour le nombre d'absorption d'un graphe simple", C. R. Acad. Sci. Paris Sér. A, 274, 728-730, 1972.

[64] M. Borowiecki, "On the External Stability Number of a Graph and its Complement", Prace Naukowe Inst. Mat. Politechniki Wroclawskiej, 12, 39-43, 1976.

[65] E.J. Cockayne, S.T. Hedetniemi, "Towards a Theory of Domination in Graph”, Networks, 7, 247 - 261, 1977.

[66] C. Payan, Sur le nombre d'absorption d'un graphe simple, in: Colloque sur la Théorie des Graphes, Paris, 1974, in: Cahiers Centre Études Recherche Opér, 17: 307 - 317, 1975 (in French).

[67] R. Laskar, K. Peters, "Vertex and Edge Domination Parameters in Graphs", Congr. Numer, 48, 291 - 305, 1985.

[68] J.P. Joseph, S.Arumugam, "Domination in graphs", Internat. J. Management Systems, 11, 177 - 182, 1995.

[69] J.E. Dunbar, T.W. Haynes, S.T. Hedetniemi, "Nordhaus - Gaddum Bounds for Domination Sums in Graphs with Specified Minimum Degree", Util. Math., 67, 97-105, 2005.

[70] L. Volkmann, "Nordhaus - Gaddum Type Results for Domination Sums in Graphs with Minimum Degree at least Four, Five or Six", Util. Math, 85, 113-128, 2011.

[71] R.C. Brigham, P.Z. Chinn, R.D. Dutton, "Vertex Domination - Critical Graphs", Networks, 18, 173 - 179, 1988.

[72] S. R. Jayaram, "Line Domination in Graphs", Graphs and Combinatorics, 3, 357 - 363, 1987.

[73] C.N. Campos, Y. Wakabayashi, "On Dominating Sets of Maximal Outerplanar Graphs", Discrete Applied Mathematics, 161, 330 $335,2013$.

[74] Tingting Zhu, Baoyindureng Wu, "Domination of Maximal $\mathrm{K}_{4}$ - Minor Free Graphs and Maximal $\mathrm{K}_{2,3}$ - Minor Free Graphs and Disproofs of Two Conjectures on Planar Graphs", Discrete Applied Mathematics, 194, 147-153, 2015.

[75] V.G. Vizing, "The Cartesian Product of Graphs", Vycisl. Sistemy, 9, 30 - 43, 1963.

[76] S. Kalavzar, N.Seifter, "Dominating Cartesian Products of Cycles", Discrete Applied Mathematics, 59, 129 - 136, 1995.

[77] R. Cherifi, S. Gravier, X. Lagraula, C. Payan, I. Zighem, "Domination Number of the Cross Product of Graphs", Discrete Applied Mathematics, 94, $101-139,1999$

[78] Liang Sun, "A Result on Vizing’s Conjecture”, Discrete Mathematics, 275, 363 - 366, 2004.

[79] M.H. El-Zahar, S.M. Khamis, M. Nazzal Kh, "On the Domination Number of the Cartesian Product of the Cycle of Length $\mathrm{n}$ and any Graph", Discrete Applied Mathematics, 155, 515 - 522, 2007.

[80] M. Pilipczuk, M. Pilipczuk, R. Skrekovski, "Some Results on Vizing's Conjecture and Related Problems", Discrete Applied Mathematics, 160, $2484-2490,2012$.

[81] M. R. Chithra, A. Vijayakumar, "Domination Critically in Product Graphs", AKCE International Journal of Graphs and Combinatorics, $12,19-25,2015$

[82] S. Gravier, A.Khelladi, "Communication on the Domination Number of Cross Products of Graphs", Discrete Mathematics, 145, 273 $277,1995$.

[83] arxiv.org/pdf/1204.0644

[84] C. E. Go, S. R. Canoy, "Domination in the Corona and Join of Graphs", International Mathematical Forum, 6( 16 ), 763 - 771, 2011. 